\title{
Director Histories and the Pattern of Acquisitions
}

\author{
Peter L. Rousseau* and Caleb Stroup ${ }^{\dagger}$
}

June 17, 2013

\begin{abstract}
We trace directors through time and across firms to study whether acquirers' access to non-public information about potential targets via their directors' past board service histories affects the market for corporate control. In a sample of publicly-traded U.S. firms, we find acquirers about 4.5 times more likely to buy firms where their directors once served. Effects are stronger when the acquirer has better corporate governance, the interlocked director has a larger ownership stake at the acquirer, or the director played an important role during past service. The findings are robust to endogeneity of board composition and controls for contemporaneous inter-firm interlocks.
\end{abstract}

KEYWORDS. Interlocking directorates; board networks; corporate governance. Jel Classification Code: G34.

*Department of Economics, Vanderbilt University, Box 1819 Station B, Nashville, TN 37235 USA. Tel: 615343 2466; Fax: 615343 8495; E-mail: Peter.L.Rousseau@Vanderbilt.Edu.

${ }^{\dagger}$ Department of Economics, Grinnell College, 1210 Park Street Grinnell, IA 50112 USA. Tel: 641269 4936; Fax: 6412694985 E-mail: stroupca@grinnell.edu. 


\section{Introduction}

It is well known that managers possess private information about their firms' operations and fundamental values. ${ }^{1}$ Information asymmetry in the market for corporate control makes it difficult for acquirers to evaluate gains associated with potential targets, thereby complicating the choice of which firms to buy. We focus on how corporate control patterns change when acquirers gain access to non-public information. In particular, we ask: Does the past board service of an acquirer's directors at other firms help to explain which targets are selected? By tracking the service histories of directors over time, we show that the answer is yes and offer evidence consistent with this occurring through the transfer of non-public information about specific targets from directors to managers. Our paper provides an example of how boards and the information available to them directly affect a major corporate decision by showing that director histories are linked acquisition target selection.

Our findings are consistent with managerial theories of corporate governance (Adams and Ferreira (2007), Harris and Raviv (2008), Song and Thakor (2006)), and with survey evidence in Demb and Neubauer (1992, pp. 43-44) indicating that most directors see themselves as active participants in setting corporate strategy. ${ }^{2}$ It is therefore not surprising that SEC merger filings offer numerous examples confirming that directors influence acquisition decisions. ${ }^{3}$

If a firm has a current director who formerly sat on the board of another firm, we

\footnotetext{
${ }^{1}$ See, for example, Myers and Majluf (1984), Travlos (1987), Eckbo, Giammarino, and Heinkel (1990), Shleifer and Vishny (2003) and Rhodes-Kropf and Viswanathan (2004).

${ }^{2}$ Hermalin and Weisbach (2003), Adams, Hermalin, and Weisbach (2010), and Finkelstein, Hambrick, and Canella (2008, ch. 8) offer useful reviews of the literature. Mace (1986) emphasizes the general passivity of corporate boards, yet also reports that boards offer expertise to managements when issues arise in which a member or members is an expert.

${ }^{3}$ For example, the S-4 form submitted in 2003 by Plug Power (a fuel cell system manufacturer operating mainly in Illinois, Indiana, Michigan and Ohio) in regard to its acquisition of H Power (a fuel cell developer and manufacturer) reports that during the Fall of 2001 and Spring of 2002 the board established a special committee of three directors to consider potential acquisitions. This committee oversaw the process that eventually led to the November 11, 2003 announcement that Plug Power intended to acquire H Power.
} 
say that there is a "historical interlock" from the current firm to the firm where the past service occurred. ${ }^{4}$ We then test for whether the existence of a historical interlock increases the probability that the current firm initiates an acquisition of the past firm relative to a firm with which it is not historically interlocked, and find that a historical interlock makes this event about 4.5 times more likely.

To distinguish between information-based explanations of our results and other possible explanations, we do a series of follow-up tests where we would expect the relation between historical interlocks and target selection to be stronger if indeed it is private information affecting the acquisition decision. We find broad support for the information-based story by documenting that the effects of historical interlocks are stronger when the acquirer has better corporate governance, which is consistent with recent theories of the labor market for directors (Levit (2012), Levit and Malenko (2012)). ${ }^{5}$ They are also stronger when the interlocked director has a larger ownership stake at the acquirer and when the director had a more important role during past service at the potential target. These factors seem to increase the likelihood that the historically-interlocked director was exposed to deal-relevant information. The effects of historical interlocks are also stronger when the acquirer cannot access non-public information about the target through contemporaneous social connections.

There are many studies that use board connections to proxy for agency issues, but most do not disentangle agency and information explanations of their results (Freeman (1979), Ishii and Xuan (2010)). Our approach allows for cleaner tests of the information explanation by distinguishing the effects of historical interlocks, which are more likely to reflect information transmission, from those of standard contemporaneous linkages (where a

\footnotetext{
${ }^{4}$ For example, A. Clinton Allen served as a director at Psychemedics Corporation, Inc. from 1989 to 2002. After leaving Psychemedics, he joined Brooks Automation, Inc. in 2003 and has served on the board ever since. In this case, we would consider Brooks Automation to be historically interlocked with Psychemedics from 2004, but not before that. At the same time, given that no current director of Psychemedics ever served on the board of Brooks Automation, Psychemedics would not have a historical interlock with Brooks.

${ }^{5}$ Levit and Malenko (2012) illustrate how stronger corporate governance can lead to boards with more outside directors who in turn influence strategic decisions more.
} 
director simultaneously sits on two firms' boards), which are more likely to reflect agency issues.

An additional advantage of historical interlocks over contemporaneous linkages is that the former are directional while the latter are not. Since we propose that historical interlocks generate information transfers, this feature allows us to test the direction of information flow between potential acquirer-target pairs. Our finding of effects only from targets to acquirers suggests that decision-makers in acquirers are more sensitive to information barriers than those in targets, and is consistent with the view that overcoming such barriers is most important when acquirers search for suitable targets.

Since directors are not randomly assigned to firms, persistent and unobserved network connectedness could undermine identification of a causal effect of information on acquisitions. Unobserved factors that might influence common director selection include governance structures, social connections, CEO entrenchment, board size, industry positioning, firm size, and organizational strategy, among others. We control for such unobserved and persistent factors with fixed-effects for each firm and firm-pair in our study and find even stronger effects of historical interlocks on the propensity to merge, which suggests that network effects specific to individual firm pairs are not driving the results. We also estimate the extent to which time-varying unobserved factors might influence director selection and find that they cannot account for our findings.

Cai and Sevilir (2011) examine how current linkages across boards tend to enhance return outcomes of completed transactions. To the extent that current links also allow for the transfer of information, albeit with more noise, we would expect to see such synergies. Our focus, however, is not on outcomes from completed deals but rather on how information influences the propensity for particular transactions to occur in the first place. ${ }^{6}$ At the same

\footnotetext{
${ }^{6}$ Studies related to ours use contemporaneous director linkages to examine how cross-firm information may affect the decisions to initiate acquisitions or joint ventures (Gulati and Westphal (1999), Schonlau and Singh (2009)), but these linkages could also arise as part of a plan for acquisition, among many other possibilities, and therefore not reflect the transfer of information about the target to the acquirer.
} 
time, we do show that historically-interlocked acquisitions have less variable announcement returns, shorter and less variable times to completion, and higher completion rates, which are all consistent with an informational interpretation. Because we examine linkages among directors within broad industrial categories, our study also relates to Custodio and Metzger (2010), though they also examine performance outcomes associated with completed deals.

There are of course many other studies where experience in executing particular actions passes across firms through director linkages. These actions include the use of poison pills (Davis (1991)), option backdating (Bizjak, Lemmon, and Whitby (2009)), repeat acquisitions (Haunschild (1993)), cross-border mergers (Stroup (2012)), and taking firms private (Stuart and Yim (2010)). But the focus on isolating the passage of deal-relevant information about a specific target through past director service is what makes our contribution unique.

The rest of the study is organized as follows. Section II develops our hypotheses and discusses a firm's exposure to non-public information through the service histories of its directors. Section III describes the historical interlock, explains how our sample of firmpairs is constructed, and presents summary statistics from our data. Section IV lays out the primary estimation framework and identification strategy and presents our main results on pair-specific merger probabilities. Section V considers a number of potential channels through which information can pass from a potential target to an acquirer and assesses the effects of historical interlocks on some performance outcomes from mergers. Section VI summarizes results of robustness tests related to alternative hypotheses, potential endogeneity, functional forms, and key decisions made in building the dataset. Section VII concludes.

\section{Literature and Hypothesis Development}

\section{A. Theoretical Motivation and Main Testable Hypotheses}

Information asymmetries are key to understanding the market for corporate control because they make it difficult for acquirers to evaluate gains associated with potential targets. Do control patterns change when acquirers have access to non-public information about a 
potential target? We formalize this question by taking the perspective of a particular acquirer whose management and board must choose a target $j$ from among a set of potential targets $j \in\{1,2, \ldots J\} .^{7}$ For simplicity, all targets are assumed to be ex-ante identical from the acquirer's perspective and acquisition gains are normally distributed as $F\left(\pi_{j}\right)$ with mean $\mu_{f}$.

We do not specify a particular interpretation for $\pi$, which could represent asset complementarities arising from scale economies (Coase (1937)), increases in market power (Salant, Switzer, and Reynolds (1983)), transfers of intangible technologies (Jovanovic and Rousseau (2002, 2008)), or liquidity constraints (Almeida, Campello, and Hackbarth (2011)), among other possibilities. The framework could also be extended to incorporate other acquisition motives such as empire building (Mueller (1969)) without altering the main prediction. ${ }^{8}$ As the foregoing indicates, $\pi_{j}$ is firm-pair specific and could depend upon information about the target's technological capabilities, managerial know-how, or overall business strategy.

The acquirer has access to an information vector $H=\left\{h_{1}, h_{2}, \ldots, h_{J}\right\}$ with $h_{j} \in\{0,1\}$. Here, $h_{j}=1$ indicates that the acquirer has exposure to non-public information about potential target $j$, in which case the acquirer observes a signal $s_{j}=\pi_{j}+e_{j}$ where $e_{j}$ is i.i.d. with zero-mean and $G(\cdot)$ is its Gaussian distribution function. For simplicity, assume $h_{k}=1$ for a single potential target $k$. The acquirer chooses between target $k$ and an unknown potential target $i \neq k$ :

$$
\max \left\{s_{k}, \max _{i \neq k} E\left[\pi_{i}\right]\right\}
$$

Within the set of unknown potential targets, the acquirer can do no better than selecting a

\footnotetext{
${ }^{7}$ In practice, not all acquisition attempts are successful and acquirers may have to compete for a single target. Allowing for these possibilities would make the analysis more complex but would not alter the main hypothesis that we develop.

${ }^{8}$ For example, Roll's (1986) framework focuses on an acquirer whose management overestimates its ability to value targets. Roll's hypothesis can be incorporated into our framework by including an acquirer-specific "hubris" term $h_{i}$ that shifts the distribution of real acquisition gains. Similarly, we could incorporate empire building or diversification motives by conditioning $F(\cdot)$ on target industry-specific effects. If acquirers prefer to buy targets with stock and targets are uncertain about whether acquirers are overvalued as in Shleifer and Vishny (2003) and Rhodes-Kropf and Viswanathan (2004), the acquisition price could involve an uncertainty premium and acquirers who prefer to pay with stock will face an additional cost $\sigma_{i}$.
} 
target at random.

Our primary empirical question is whether a known potential target is more likely to be acquired than an unknown one, i.e., whether reductions in information frictions promote acquisitions. Let $A_{j}=1$ if the acquirer buys target $j$ and zero otherwise, so that we can pose the question as whether $B$ is greater, less than, or equal to one, where

$$
B=\frac{p\left(A_{j}=1 \mid h_{j}=1\right)}{p\left(A_{j}=1 \mid h_{j}=0\right)} .
$$

This formulation is useful since the relative probability of acquisition will not be affected by extraneous factors influencing the overall probability that firms are acquired such as acquirer characteristics or industry-wide merger waves, at least to the extent that such factors influence known and unknown targets equally.

It is not obvious that $B>1$, since acquirers may have private information revealing a potential target to be a poor acquisition candidate. To examine this, first consider the case where the signal reveals favorable information about firm $k$, i.e. $s_{k}-\mu_{f} \geq 0$. Equation (1) implies that the known target will always be selected in this case: $p\left(A_{k}=1 \mid h_{k}=\right.$ $\left.1, s_{k}-\mu_{f}>0\right)=1$. Let $K$ be the c.d.f. of $s$, which by unbiasedness of $e_{j}$ has mean $\mu_{f}$. Symmetry of $K$ implies that $p\left(s_{k}-\mu_{f} \leq 0\right)=K\left(\mu_{f}\right)=1 / 2$. Bayes theorem implies $p\left(A_{k}=1 \mid h_{k}=1\right)=p\left(A_{k}=1 \cap s_{k}-\mu_{f}>0\right)=1 / 2$. When unfavorable information is revealed about the potential target $\left(s_{k}-\mu_{f} \leq 0\right)$, the acquirer will draw an unknown target, i.e., $p\left(A_{i}=1 \mid s_{k}-\mu_{f}<0\right)=1 /(J-1)$. Using this result along with $K\left(\mu_{f}\right)=1 / 2$ and Bayes theorem yields $p\left(A_{i}=1 \mid h_{i}=0\right)=p\left(A_{i}=1 \cap s_{k}-\mu_{f} \leq 0\right)=1 /(2(J-1))$.

Applying these findings to an arbitrary firm $j$ gives $B=J-1>0$, which is just the relative probability that the known target will be acquired. The mechanism is simple: known targets are more likely to be acquired relative to unknown targets since positive information allows a potential acquirer to avoid negative outcomes in the distribution of unknown synergies. This leads to our main hypothesis. 
Hypothesis 1: Acquirers are more likely to buy firms about which they have access to nonpublic information, relative to others.

To put this result in perspective, suppose $J=11$, in which case $p\left(A_{i}=1 \cap s_{i}-\mu_{f}>0\right)=1 / 2$ and $p\left(A_{j}=1 \cap s_{i}-\mu_{f} \leq 0\right)=1 / 20$, so known targets would be ten times more likely to be acquired than unknown targets. Our setup is clearly stylized, yet its main prediction can hold even when known potential targets are worse on average relative to other acquisition candidates $\left(e_{t}\right.$ is centered below zero) if acquirers have information about multiple targets or if selection of unknown targets is non-random.

There are two additional paths, in addition to the mechanism described above, through which information about acquisition synergies could lead acquirers to buy known targets. First, given that acquisitions typically involve large capital outlays, risk-averse managements or boards may prefer to avoid bad outcomes by bidding for a target about which information is known. This could occur even if the expected gain is worse than that associated with acquisition of an average unknown firm.

The second possibility is motivated by Rhodes-Kropf and Robinson (2008), who model mergers as the outcome of a costly search process. This prior is supported by Bruner (2004) p. 183, who views acquisition search as an information-gathering process focused on obtaining "deal-rich" information, a key component of which is non-public. In this case, access to non-public information about a potential target reduces search costs associated with that particular firm and leads acquirers to prioritize known targets in their search queues. When risk aversion or search costs are present, the degree of information asymmetry between known and unknown targets will affect the difference in the acquirer's likelihood of bidding on a known relative to an unknown target.

Thus far we have focused on the perspective of a potential acquirer. Yet potential targets may also value information about firms that attempt to acquire them. This can occur if targets are concerned about being bought with overvalued stock so that information about 
the acquirer is relevant in deciding whether or not to accept an exchange offer. A second possibility is that targets facing a hostile takeover may find non-public information useful in selecting a white knight (i.e., alternative acquirer). Since white knight outcomes are far more rare than acquisitions themselves, it may be that this "reverse information flow" effect is weak in practice. Under the assumption that targets receive deal relevant information from current directors through their prior service at potential acquirers, our framework is easily modified to formulate a testable alternative hypothesis using our directed pairs:

Hypothesis 2: Targets are more likely to merge with acquirers about which they have access to non-public information, relative to others.

To test these hypotheses, we now turn to motivating and constructing a measure of a firm's exposure to non-public information about potential targets.

\section{B. Measuring Cross-Firm Information Asymmetries}

An ideal measure of an acquiring firm's access to information about a potential target would perfectly isolate this from other factors affecting mergers. While no ideal measure exists, our "historical interlocks" are more likely than the common alternatives to meet this criterion. To guide the analysis, we now review the literature on cross-firm information asymmetries to motivate our use of the "historical interlock" as a measure of information exposure.

A well developed literature quantifies the degree of information asymmetry between a given firm and other market participants. Some authors propose that asymmetries are largest when analysts disagree about a firm's prospects (Krishnaswami and Subramaniam (1999), Moeller, Schlingemann, and Stulz (2007)), while others relate valuation difficulties to the idiosyncratic component of stock prices (Dierkens (1991)), the quality of a firm's accounting information (McNichols and Stubben (2009)), or the existence and size of a defined benefit pension plan (Cocco and Volpin (2009)). 
In contrast, we focus on a firm's decision to acquire a specific target. This requires a measure of information frictions that varies across potential acquirers for each potential target and vice-versa. By supposing that directors at an acquirer are exposed to information about a potential target through past service on the target's board of directors, we define a "historical interlock" for a potential acquirer as a binary indicator that varies at the firm-pair level. We then build a comprehensive set of ordered annual firm-pairs, where some involve an acquisition of the second firm in the pair by the first and many others do not, and assess how historical interlocks and other measures of target desirability affect the probability of such acquisitions. ${ }^{9}$

Historical interlocks by construction isolate instances where a current director at a given firm served on the board of a prospective target more than two years ago, but has not since served there. An alternative would be to measure inter-firm information transfers with contemporaneous interlocks. Indeed, while it is natural to suppose that information about corporate practices can be transmitted through current linkages, they are more likely than historical interlocks to reflect agency conflicts or strategic effects unrelated to the transfer of private information. Among other possibilities, these factors could include knowledge about a firm's current negotiating position or a tendency to "stack" the target's board with directors from the acquirer shortly before announcing a merger. ${ }^{10}$ The existence of such agency conflicts, if only in the minds of investors, may alter acquisition decisions in ways that are unrelated to the transfer of information. Since contemporaneous interlocks may simultaneously confer information and involve strategic effects, their interpretation in this

\footnotetext{
${ }^{9}$ This implies that in each year, subject to data availability from Compustat, we include all possible ordered firm-pairs that have director information in the IRRC Directors Database, i.e., our sample allows any firm to be an ex ante potential acquirer of any other - small or large. For computational feasibility, we will restrict the main analysis to firm pairs where both firms lie in the same major (10-category) SIC division. Section III.B provides a detailed description of how we create the dataset used in the econometric analysis.

${ }^{10}$ These practices under certain circumstances could be seen as a breach of the director's fiduciary responsibility. For example, the S-4 form submitted by Capitol Bancorp is connection with its 2001 acquisition of Sun Community Bancorp Ltd. reports that concerns were raised during the pre-announcement negotiations about conflicts of interest because the two firms had a common director.
} 
context is not clear.

An additional advantage of historical interlocks is that, unlike contemporaneous interlocks, they are 'directed' in the sense that if firm $i$ is historically-interlocked with firm $j$ in year $t$ through a director $k$, it follows that director $k$ has a fiduciary responsibility to firm $i$ and not to firm $j$ in year $t$. It is also less likely that director $k$ would have obtained non-public information about firm $i$ while serving on the board of firm $j$ unless he had served on both boards simultaneously in the past but had stepped down from only firm $j$. This directedness allows us to test whether private information matters more for an acquirer seeking a target or for a target seeking an acquirer.

The directedness of historical interlocks also allows us to test for a broad alternative hypothesis that we refer to as "director-firm matching" or "spurious correlation," which could arise because similar firms are more likely to hire the same directors. ${ }^{11}$ Because similar firms are also more likely to merge, an observed correlation between director connections and acquisitions could reflect these unobserved common characteristics. For example, directors with experience in a particular industry are likely to be hired by firms in that industry. ${ }^{12}$ This hypothesis predicts that either firm will be as likely as the other to become the acquirer, which we can assess by looking at the effect of reverse historical interlocks on acquisition patterns.

A potential concern associated with all forms of inter-firm connections is that linked directors' decision-making is dominated by psychological biases (Asch (1951), Freeman (1979), Gulati and Westphal (1999)). For example, directors influenced by familiarity bias (i.e., social connections) might attempt to pressure their boards to bid on firms where they once

\footnotetext{
${ }^{11}$ The theoretical literature rationalizes this observation by noting that optimal board structure should depend on firm characteristics (Hermalin and Weisbach (2003), Adams, Hermalin, and Weisbach (2010)).

${ }^{12}$ Even outside the context of directors, an observed relationship between firm actions and mergers could reflect such unobserved firm-pair similarity. For example, Higgins and Rodriguez (2006) study the wealth effects of mergers among firms that have prior business alliances. Gompers and Xuan (2009) measure the extent to which problems of asymmetric information are smaller among common pools of venture capital investors relative to independent venture capitalists, and find that having common venture capital investors increases the probability of a merger.
} 
served. We will refer to variants of the bias hypothesis collectively as "psychological biases" even though they could reflect agency concerns as well, and test for whether these channels are also at play.

\section{Data and Experience Measures}

\section{A. Directors and Historical Interlocks}

Our main measure of inter-firm director connections is the historical interlock, which takes a value of unity for a potential acquirer in year $t$ if at least one of its current directors served on the potential target's board in the past, but not in the past two years. In other words, for each firm in our sample there are potential matches with a universe of possible targets, each of which is characterized by the presence or absence of a historical interlock. Historical interlocks are thus meant to isolate situations where information about a target is all that likely remains with the potential acquirer and where the reverse (i.e., information transfer from acquirer to target) is much less likely.

Figure 1 illustrates the historical interlock. The three horizontal timelines reflect board service at different firms by a single director. In the figure, our hypothetical director served on the board of firm A prior to 2000 at which point he left firm A and joined the board of firm B. He also served from 1997 to 2003 at firm C. The definitions given above imply that firm B has a historical interlock with firm A from 2002 onward and that firm C has a historical interlock with firm A from 2002 to 2003. Further, firm B would have a historical interlock with firm C from 2006 onward.

As discussed in Section I, the historical interlock stands in contrast with standard (i.e., contemporaneous) interlocks, which are defined for an acquirer $i$ in year $t$ as the presence of a current board member sitting, at period $t$, on a potential target's board. This implies that one of the potential target's current directors also sits on the acquirer's board so that, unlike historical interlocks, every contemporaneous linkage reflects two interlocks, with one in each direction. Figure 1 also illustrates the contemporaneous interlock. Here, firm B is contem- 


\section{Figure 1}

\section{Director Movements and the Historical Interlock}
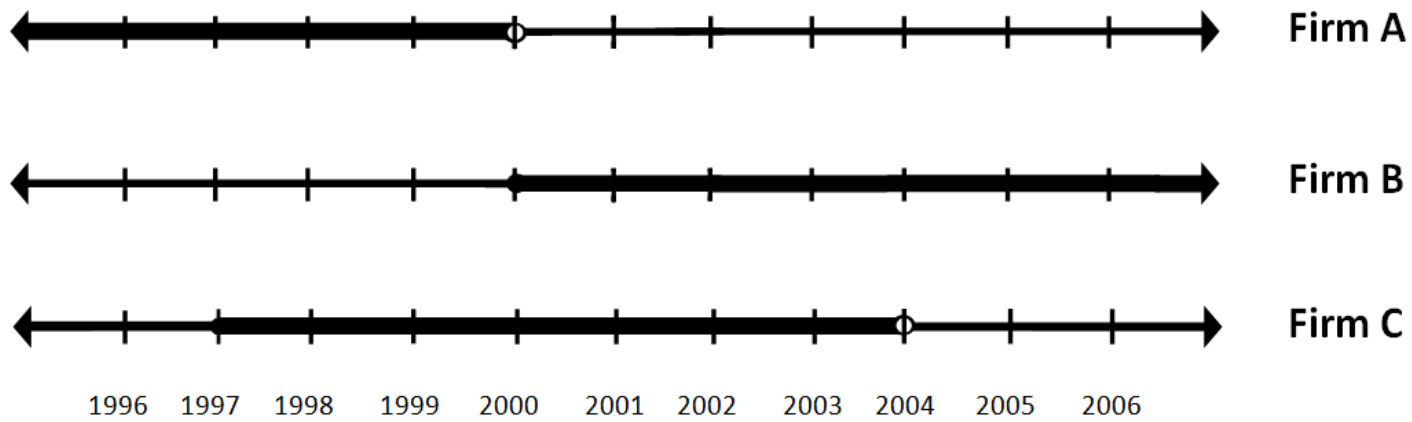

Board service by director $k$

\begin{tabular}{|c|c|c|}
\hline Ordered pair & Historical Interlock & Contemporaneous Interlock \\
\hline A to $\mathrm{B}$ & none & none \\
\hline A to $\mathrm{C}$ & none & 1997-1999 \\
\hline $\mathrm{B}$ to $\mathrm{A}$ & 2002- & none \\
\hline $\mathrm{B}$ to $\mathrm{C}$ & 2006- & 2001-2003 \\
\hline $\mathrm{C}$ to $\mathrm{A}$ & $2002-2003$ & 1997-1999 \\
\hline $\mathrm{C}$ to $\mathrm{B}$ & none & $2001-2003$ \\
\hline
\end{tabular}

poraneously interlocked with firm C (and vice-versa) from 2001-2003 and firm A is contemporaneously interlocked with firm C (and vice-versa) from 1997-1999. ${ }^{13}$

\section{B. Sample Creation and Descriptive Statistics}

We use information on the service histories of individual directors from the Investor Responsibility Research Center, Inc. (IRRC) Directors Database to identify historical and contemporaneous interlocks. ${ }^{14}$ Along with board service records, the Directors Database

\footnotetext{
${ }^{13}$ The annual data reported in the IRRC obscures the fact that annual meetings and thus director appointments occur throughout the year. This complicates the decision of how to classify directors given that in some instances no cross-firm overlap occurs within years while in others there are varying degrees of overlap. We take a conservative approach and count firms as contemporaneously interlocked only in those cases where the director served on both boards in the prior year, as illustrated in Figure 1.

${ }^{14}$ These data are primarily from company proxy statements but also include some director information from company annual reports and websites. They include directors who served at firms listed in the Standard and Poor's (S\&P) 1500, which covers approximately $90 \%$ of U.S. stock market capitalization.
} 
also characterizes directors in each year as corporate executives, inside directors, former employees, and/or professional directors, among other roles.

Table 1 shows summary statistics on cross-firm seatings obtained by tracking the 26,797 directors in the IRRC across firms and over time. The left-hand side of Panel A, which shows the distribution of the total number of firms at which each director served, indicates that $22.4 \%$ of directors served at only one firm over the 1996-2006 period, thus generating no interlocks. At the same time, $69 \%$ of directors served on five boards or fewer. To understand whether the multiple board seatings resulted primarily from simultaneous appointments or from director movements from firm to firm, the right-hand side of Panel A shows the distribution of simultaneous seatings at the director-year level. The majority (81.1\%) of annual seatings involve directors who serve on the board of a single firm, $12.8 \%$ involve directors who sit simultaneously on the boards of two firms, and $5.9 \%$ involve directors serving three to five firms. This indicates that most cross-firm director connections occur through movements across firms over time, and are thus historical in nature rather than contemporaneous.

\section{[Table 1 here]}

Panel $\mathrm{B}$ of Table 1 indicates the roles played at the potential acquirer and target for both historically and contemporaneously-interlocked directors. For example, 38.7\% of historically-interlocked directors were executives at the "current" firm and $25.1 \%$ were inside directors at the current firm, and $36.4 \%$ and $32.7 \%$ were executives and inside directors, respectively, during the "past" board assignment. Contemporaneously-interlocked directors, on the other hand, were more likely to be executives (43.6\%) and less likely to be professional (i.e., "career") directors $(4.2 \%)$ than were historically-interlocked directors. ${ }^{15}$.

Our main data set, an unbalanced panel of ordered $(i, j)$ firm pairs, combines the in-

\footnotetext{
${ }^{15}$ The right-hand side of panel B counts each simultaneous directorship in the sample separately since a director may have different roles at the firms where contemporaneous service occurs.
} 
formation on historical and contemporaneous interlocks with data from Standard and Poor's Compustat and Thomson's SDC Platinum databases. Intuitively, our approach requires three fundamental items: an ordered firm pair $(i, j)$, an indicator for whether firm $i$ is historically interlocked with firm $j$, and an indicator for whether firm $i$ acquires firm $j$. This is conceptually similar to Rhodes-Kropf and Robinson (2008) who study the effect of similarity in the market-to-book ratios of firm pairs on the probability that the two firms merge.

The data set is constructed as follows. We first identify a computationally feasible sample of ordered firm pairs from Compustat by retaining all possible ordered firm-pairs over the 1996-2006 period where firm $i$ and firm $j$ lie in the same major 10-category SIC division. ${ }^{16}$ We next identify and retain those firm pairs for which we have directors data and at least two years of Compustat data for both firms. This leaves a sample of 1,401,955 ordered firm pairs, or 12,703,425 firm-pair-year observations. For each firm pair, we then set indicator variables for whether, in each year, firm $i$ was historically or contemporaneously interlocked with firm $j$. It turns out that 4,488 annual firm pairs have a historical interlock. Finally, we use the $S D C$ Platinum database to set an indicator variable for whether, in each year, firm $i$ acquired firm $j$, with acquisitions defined as deals with value greater than $\$ 1$ million that involve acquisition of at least $20 \%$ of the target's shares and would result in a controlling interest in the target. ${ }^{17}$ This results in 612 cases where firm $i$ acquires firm $j$.

Our procedure generates a reasonably representative sample of Compustat firms, but as well known in the literature on rare events, also leads to downward biases in the estimated effects of historical interlocks on merger pairings. To mitigate this, we impose the additional

\footnotetext{
${ }^{16}$ The 10 major SIC divisions are: (a) agriculture, forestry, and fishing; (b) mining; (c) construction; (d) manufacturing; (e) transportation, communications, electric, gas, and sanitary services; (f) wholesale trade; (g) retail trade; (h) finance, insurance, and real estate; (i) services; and (j) public administration. Using more disaggregated industries is infeasible computationally because the probability models that we estimate in Section IV and Section V below would require a separate industry effect for every possible combination of industry codes.

${ }^{17}$ These restrictions focus attention on situations where the deal is more likely to represent a major capital investment by the acquirer, i.e., be classified as a merger rather than a portfolio investment.
} 
restriction that the potential acquirer be no smaller than 75 percent of the potential target, with size measured as a firm's total assets. This restriction creates a sample where mergers are more likely since in practice it is much more common for larger acquirers to buy smaller targets. This eliminates about 45 percent of non-merging and 8 percent of merging pairs from the sample, leaving us with 6,984,098 firm-pair observations. ${ }^{18}$

Panel A of Table 2 compares acquirer and target characteristics of firms in our sample with average characteristics of S\&P 1500 firms. Consistent with previous studies, acquirers are larger, have higher free cash flow, are less leveraged, and have lower sales-to-asset ratios but higher market-to-book ratios, while targets are more similar to the average S\&P 1500 firm.

\section{[Table 2 here]}

Panel B shows that $9.1 \%$ of merging firm pairs were historically interlocked and that $6.3 \%$ of merging firm-pairs were contemporaneously interlocked. ${ }^{19}$

\section{Baseline Findings}

In this section we present our baseline findings, describing the estimation approach as we proceed. Our aim is to estimate the effect of a historical interlock between firm $i$ and potential target $j$ on the probability that firm $i$ acquires $j$. Consider the following algebraic reformulation of equation (2):

$$
\operatorname{Pr}\left(A C Q_{i j t}=1 \mid H_{i j t}=1\right)-\operatorname{Pr}\left(A C Q_{i j t}=1 \mid H_{i j t}=0\right)
$$

where $A C Q_{i j t}$ takes a value of unity if firm $i$ announces an acquisition of target $j$ in year $t$

\footnotetext{
${ }^{18} \mathrm{We}$ also experimented with no relative size restriction and with cutoffs set at 1 and 1.33 , and found that the effects of historical interlocks on acquistions increased with the aggressivity of the cutoff.

${ }^{19}$ Computational feasibility is not a concern when we analyze deal outcomes in Section V.E below because we do not need information on non-merging firm pairs. In these cases we relax the restriction that the acquirer and target lie in the same major 10-category SIC division and use the full sample of 809 announced acquisitions shown in Panel B.
} 
and zero otherwise, and $H_{i j t}$ is an indicator set to unity if firm $i$ has a current director with a historical interlock to firm $j$ in year $t$ and zero otherwise.

We estimate the partial effect in (3) with the baseline logit equation:

$$
\operatorname{Pr}\left(A C Q_{i j t}=1\right)=G\left(\beta_{1} H_{i j t}+\beta_{2} I_{i j t}+\gamma X_{i j t}+\tau_{t}+w_{k}+\varepsilon_{i j t}\right)
$$

where $\beta_{1}$ is the coefficient of interest, $I_{i j t}$ is an indicator set to unity if firm $i$ has a contemporaneous interlock with potential target $j$ in year $t$ and zero otherwise, and $X_{i j t}$ represents a vector of firm-pair specific control variables that may affect the probability that the two firms merge. Intuitively, equation (4) asks whether a historical interlock from $i$ to firm $j$ associates with a higher probability that $i$ acquires $j .{ }^{20}$ We include year $\left(\tau_{t}\right)$ and industry $\left(w_{k}\right)$ fixed effects because merger waves tend to cluster along these dimensions (Harford (2005)), and we account for arbitrary correlations in acquisition probabilities between individual firm pairs by clustering standard errors at the ordered-pair level. We estimate (4) using the set of ordered firm-pairs described in Section III.B.

Table 3 presents the results. Column (1) shows that the coefficient for a historical interlock is positive and statistically significant, which is consistent with the Hypothesis 1, namely that acquirers are more likely to buy firms about which they have access to nonpublic information, and in this case through directors' service histories. Column (2) adds contemporaneous interlocks, which also enter positively and are statistically significant. We add several controls in column (3). These include measures of relative size (i.e., the ratio of acquirer-to-target total assets), relative sales productivity (sales-to-assets ratios), and relative market valuation (market-to-book ratios), all of which could reflect increased investment opportunities or overvaluation and lead to a greater probability of an acquisition (Jovanovic

\footnotetext{
${ }^{20}$ Shumway (2001) demonstrates the equivalence between the multi-period binary response model that we use and hazard models, implying that the marginal effect associated with $\beta_{1}$ can be interpreted as that of a historical interlock on the probability that firm $i$ acquires target $j$ in year $t$.
} 
and Rousseau (2002, 2008), Harford (2005), Dong et al. (2006)). ${ }^{21}$ We add two measures of network connectedness among firm pairs in column (4) which are dummy variables set to unity when the acquirer and potential target are in the same 4-digit SIC industry or are headquartered in the same county (Hoberg and Phillips (2010)). ${ }^{22}$ The main specification in column (5) includes fixed effects for the major (10-category) SIC division of each firm pair.

The key finding is that these controls do not affect the sign or statistical significance of the estimated coefficient on historical interlocks, though it is slightly smaller in columns (4) and (5), which suggests that historical interlocks are positively correlated with measures of network connectedness. Turning to the other controls, a potential acquirer is more likely to buy a given potential target when the former is relatively larger and more highly valued than the latter. The relative sales-to-assets ratio is unrelated to likelihood of a merger.

\section{[Table 3 here]}

We assess the economic magnitudes of the estimated effects using the odd's ratio

\footnotetext{
${ }^{21}$ Total assets is Compustat item 6, sales is item 12, and cash is item 1 . The leverage ratio is the sum of short and long-term debt (items 34 and 9) divided by item 6 . We measure the numerator of the market-tobook ratio as the value of a firm's common equity at current share prices (the product of items 24 and 25), to which we add the book values of preferred stock (item 130) and short- and long-term debt (items 34 and 9 ). We use book values of preferred stock and debt in the numerator because prices of preferred stock are not available on Compustat and we do not have information on issue dates for debt from which we might better estimate market value. We note that book values of these components are reasonable approximations of market values in stable interest rate environments such as the U.S. during our sample period. We compute the denominator in the same way except that we use the book value of common equity (item 60) rather than its market value. We eliminate firms with negative values for net common equity from the sample since they imply negative market-to-book ratios, as well as observations with market-to-book ratios in the top $0.5 \%$ of the distribution, which yields a cutoff market-to-book value of 34.1, since these are likely to reflect data errors. Robustness tests (not reported) indicate that our main results are robust to alternative upper cutoffs at the top $5 \%$ and $1 \%$ of the distribution, which corresponds to market-to-book ratios of 10.1 and 20.0 respectively.

The sales-to-asset ratio (Compustat item 12 divided by item 6) is our proxy for TFP because individual firm output is not available on Compustat. Leverage is given by the ratio of short and long-term debt to total assets (the sum of Compustat items 34 and 9 divided by item 6).

${ }^{22}$ While the sample is already restricted to firm pairs that reside in the same major (10-category) SIC division, including an indicator in the logit model for whether the pair are also in the same 4-digit SIC category controls for the possibility of much stronger network connectedness due to the closeness of the two firms' core functions.
} 
evaluated at the covariate means. ${ }^{23}$ First and foremost, acquirers are 4.5 times more likely to initiate purchases of potential targets with which they are historically interlocked. The probability of an acquisition rises by $6.8 \%$ in response to a one standard deviation increase in relative firm size and by $3.4 \%$ for a one standard deviation increase in relative marketto-book ratios. The same-county effect is also strong, with two firms from the same county being $9.3 \%$ more likely to merge relative to an average firm pair. Firms within the same 4-digit SIC industry are $80 \%$ more likely to merge relative to those across 4 -digit industries.

\section{Potential Channels}

We now examine the extent to which historical interlocks reflect information transmission and conduct tests to see whether there is evidence in favor of an alternative interpretation. These tests strengthen the argument made later that director selection is not driving our results.

\section{A. Does the Direction of Information Flow Matter?}

Our prior is that information available to acquirers through a current board member's earlier service can be useful in selecting targets, and our illustrative model suggests how this may occur. An alternative is that the relevant flow of information runs in the opposite direction. For example, if a target believes that acquirers are generally overvalued and a proposed merger involves an exchange of shares, information gained by one of the target's current directors during past service at the acquirer could reduce uncertainty about the value of the shares being offered relative to an unknown acquirer, making the target more likely to accept this particular offer. Alternatively, the target of a hostile takeover may be more likely to recruit as white knights those acquirers with which they have a historical interlock.

\footnotetext{
${ }^{23}$ Marginal effects of covariates on the dependent variable are obtained in the usual manner given coefficient estimates for a $d x_{i}$ change in covariate $i$ : $\frac{\partial \operatorname{Pr}\left(A c q_{i t}=1\right)}{\partial x_{i t}}=G^{\prime}(o d d s(X)) \gamma_{i}$ where $o d d s(X)$ is the odds ratio constructed using the estimated coefficients and is evaluated at the mean value of covariates: odds $(X)=$ $\exp \left(\alpha_{1} H_{i t}^{C}+\gamma X_{i, t}+\tau_{t}+w_{k}\right)$.
} 
We test for the direction of information flow by constructing "reverse historical interlocks," which are simply historical interlocks from targets to potential acquirers. Formally, we define a reverse historical interlock for an acquirer when, in year $t$, one of the potential target's current directors once served on the acquirer's board but has not in the past two years. Here, we re-estimate equation (4) and include the reverse historical interlock in the equation to examine if it, like the historical interlock, has any predictive power. Note that the sample includes both actual and potential acquirers, so there is no a priori distinction made between direct and reverse historical interlocks in terms of acquirer or target characteristics. Including reverse historical interlocks in our regressions also tests indirectly for whether our historical interlocks reflect network connectivity or spurious director-firm matching, since both of these alternative interpretations predict a positive and equivalent effect of either type of interlock.

Table 4 presents the results. The first row shows that historical interlocks remain associated with a higher probability that, for firm pair $i j$ in year $t$, firm $i$ will announce an acquisition of $j$. The second row, on the other hand, shows that reverse historical interlocks are not statistically significant whether or not historical interlocks are included in the regression, except possibly with a negative effect at the $10 \%$ level when we omit control variables. Comparing Table 3 with Table 4, there is no evidence that the inclusion of reverse historical interlocks attenuates the effect of historical interlocks. These results suggest that the direction of inter-firm connections does matter, and is consistent with our hypothesis that access to non-public information is more important for acquirers than for targets. This is perhaps unsurprising given that targets, at least in the case of cash deals, need only care about the price received rather than acquirers who must also consider synergies associated with a particular deal.

\section{[Table 4 here]}




\section{B. Does a Director's Role Influence the Effect of a Historical Interlock?}

We now consider a number of director characteristics and how they affect the explanatory power of historical interlocks. We do this because understanding how various forms of director heterogeneity affect target choice can help to distinguish whether historical interlocks predominantly reflect factors other than the transfer of information. For example, while the information view of historical interlocks predicts that non-public information about potential targets will affect merger decisions, the psychological bias interpretation is more closely related to the extent of an interlocked director's influence over the acquirer's board. To explore these effects, we first interact historical interlocks with indicators set to unity if a historically-interlocked director is an executive or inside director at the acquirer. ${ }^{24}$ This of course presumes that executives and insiders can influence acquisitions more than other board members.

Columns (1) and (2) of Table 5 report estimates from adding these interactions to the baseline specification (i.e., the logit model in column (5) of Table 3). A positive coefficient for either interaction would suggest that director influence, and thus psychological bias, can explain at least part of the effect of historical interlocks on target choice. The coefficient estimates are both negative and not statistically significant, however, and their inclusion does not affect the sign, statistical significance, or overall magnitude of the direct coefficients on historical interlocks.

\section{[Table 5 here]}

Second, if the information hypothesis predominates in historical interlocks, their effects should be strong when a historically-interlocked director at the acquirer has a significant ownership stake there. This is because stakeholding directors are less likely to let factors such as inattention, psychological bias, or maintaining social connections influence their decisions.

\footnotetext{
${ }^{24}$ Information on individual directors' roles and ownership stakes is available from the IRRC.
} 
We test this by interacting historical interlocks with an indicator set to unity if the director has a stake of less than $1 \%$ of the acquirer's stock and zero otherwise. Column (3) of Table 5 shows that this interaction is indeed negative and statistically significant and that the direct effect of historical interlocks becomes larger.

Third, the information hypothesis predicts that information about potential targets will affect merger decisions more when the historically-interlocked director played an important role on the target's board during service there, since in these cases access to relevant non-public information about the target is likely to have been greater. In this case, we interact historical interlocks with indicators set to unity when the historically-interlocked director was once an executive, inside director or former employee of the target. Columns (4), (5) and (6) of Table 5 add these interactions to the baseline specification, and in all three cases the effect of historical interlocks continues to be positive, statistically significant, and similar in magnitude to the main estimates. ${ }^{25}$ At the same time, and consistent with the information interpretation, the interaction terms are also positive and statistically significant. ${ }^{26}$

\section{Historical Interlocks and Corporate Governance}

Psychological bias and network connections may dominate decision-making in firms with poor corporate governance (Masulis et al. (2007)). To test whether historical interlocks are influenced by firm-level governance, we collect data from the IRRC Corporate

\footnotetext{
${ }^{25}$ We also examined whether the tenure of the historically-interlocked director at the target firm influences the results and found a small effect that is statistically significant at the $10 \%$ level. We next tested whether adding a second historically-interlocked director would influence merger patterns and did not find an additional effect associated with more than one historical interlock between the two firms.

${ }^{26}$ Another possible factor affecting the explanatory power of historical interlocks is that the director received shares at the target firm during his service there. In this case, the director may find himself years later in an influential position at the acquiring firm so that he can influence the choice of a target. Being aware of the premium that will be offered for the target shares, the director would then have a personal reason for supporting the acquisition of that particular target.

Although we do not have information about a current director's shareholdings of the potential target's shares at the time of acquisition, we do know whether the director held more than $1 \%$ of the target's shares the year he ended service there. When we include the interaction between historical interlocks and the dummy variable for previous target ownership, however, it is not statistically significant. We thank an anonymous referee for pointing this possibility out to us.
} 
Takeover Defenses Database, which includes an index of overall governance quality originally constructed by Gompers, Metrick, and Ishii (2003) as well as information on individual governance provisions. If historical interlocks affect merger decisions more strongly for firms with weak governance provisions regarding agency conflicts between directors and shareholders, this would offer support for one or both of the alternative theories. We examine three characteristics of the acquiring firm's board. First, under "duties" provisions, directors are not precluded from acting in the interests of non-shareholders when evaluating an acquisition. Second, when the firm has indemnification contracts in place, directors are protected from certain legal actions such as lawsuits filed by shareholders for perceived breaches of fiduciary responsibility. Finally, "care" provisions limit director liability arising from breaches of their "duty of care." 27

The requirement that governance data be available for each potential acquirer reduces the number of observations in our sample by $67 \%$. This is due to the Gompers at al. (2003) index covering only five years of our sample $(1998,2000,2002,2004,2006)$, our own sampling restrictions described in Section III.B, and changes in the composition of the S\&P 1500 over time. To facilitate comparisons with our earlier results, we therefore re-estimate the baseline regression reported in column (5) of Table 3 using only those observations for which governance data is available for the acquirer. The results appear in column (1) of Table 6, and indicate that the effect of historical interlocks on the probability of merging is still positive and statistically significant but smaller in magnitude than that obtained with the unrestricted sample. Columns (2), (3) and (4) add interactions of historical interlocks with indicators for the "duties," "contract," and "care" provisions along with the individual indicators for these variables, though we suppress the latter coefficient estimates to conserve space. ${ }^{28}$ The interactions are not statistically significant and the direct effects of historical

\footnotetext{
${ }^{27}$ A director's "duty of care" is a responsibility to be informed and active when making decisions and to use prudence and sound judgment.

${ }^{28}$ The coefficient on "duties" is not statistically significant, while that on "contract" is positive and signif-
} 
interlocks are largely unaffected, which is opposite to the predictions of network connections and psychological bias theories.

\section{[Table 6 here]}

Next, we interact historical interlocks with the index of corporate governance, which is defined so that larger values reflect weaker governance. In doing so, we ask whether the effect of historical interlocks on target selection is stronger when the acquirer has weak governance. A positive coefficient on the interaction term would answer in the affirmative and offer support for the network connections or psychological bias theories. The regression reported in column (5) of Table 6 , however, indicates a negative and statistically significant coefficient on the interaction term, which is consistent with a stronger effect of historical interlocks for acquirers with good governance.

In Columns (6) and (7) we interact historical interlocks with two additional measures of governance that address acquisitions specifically. Control-share acquisition laws deny voting rights to newly-qualified large shareholders unless approved by a majority of disinterested shareholders, while supermajority provisions allow increases in the voting threshold needed to approve deals beyond state-level mandates so that mergers are less easily approved by shareholders. Neither of these terms are statistically significant when interacted with historical interlocks, however, and neither affects the magnitude of the direct effect of a historical interlock. These tests offer additional evidence that historical interlocks do not lead to acquisitions driven by value-destroying motives.

\section{Historical Interlocks and Target Unfamiliarity}

If historical interlocks reflect information that is useful for valuing targets, we would expect them to affect target choice more in environments where the deal is difficult to value.

icant at the $10 \%$ level and that on "care" is positive and significant at the $1 \%$ level. In columns (5)-(7) of Table 6 the coefficients on G-index and "supermajority" are not statistically significant but the coefficient on "control-share" is positive and significant at the $10 \%$ level. 
Though an imperfect indicator of informational proximity, difficulties in valuation could be related to geographic positioning such as whether or not the two firms in a pair are headquartered in the same county. For example, it is common for executives in California's "Silicon Valley" to share ideas through social and network connections, and their relative proximity facilitates such exchanges.

To explore these implications, we interact historical interlocks with an indicator set to unity when the potential acquirer and target are headquartered in the same county. The information hypothesis predicts that these interactions will have a negative effect on target selection since the degree of overlapping non-public information provided by directors is likely to be smaller.

\section{[Table 7 here]}

Table 7 presents the results. In the first row we re-estimate the baseline specification of equation (4) including the interaction of historical interlocks with the same-county indicator on the right-hand side. This term enters negatively and is statistically significant, indicating that the effect of historical interlocks is greater for firm-pairs where information asymmetries are likely to be largest. Column (2) performs an analogous exercise for contemporaneous interlocks and finds no such effect. In column (3) we include the interactions of both historical and contemporaneous interlocks with the same-county dummy. In this case we find that the interaction with historical interlocks continues to enter negatively and at the $1 \%$ level while the interaction with contemporaneous interlocks is not statistically significant.

\section{E. Historical Interlocks and Deal Outcomes}

If historical interlocks provide a conduit for transmission of non-public information, we would expect to find performance-based evidence consistent with this advantage. In particular, more informed deals should be associated with higher or less variable announcement returns on average, and should have a lower incidence of extreme negative returns. Mergers among historically-interlocked firms should also have higher probabilities of completion 
and shorter lags between announcement and effective dates. In this section we explore the effects of historical interlocks on these outcome measures. Since the tests only require data on actual deals, we work with all announced mergers for which acquirer and target are both in the IRRC database and have the required balance sheet items available from Compustat, and we do not restrict the sample to deals within major (10-category) SIC industries.

\section{Announcement Returns}

We begin by estimating an OLS regression of abnormal returns around the announcement day:

$$
C A R_{i j t}=\alpha_{1}+\alpha_{2} H_{i j t}+\alpha_{4} I_{i j t}+\alpha_{5} Z_{i j t}+\tau_{t}+\varepsilon_{i j t}
$$

where $C A R_{i j t}$ is the acquirer's cumulative abnormal return after a merger is announced between firm $i$ and $j$ in year $t, H_{i j t}$ and $I_{i j t}$ represent historical and contemporanrous interlocks, the $Z_{i j t}$ are deal characteristics, and the $\tau_{t}$ are fixed effects for years. We calculate abnormal percentage returns using standard event study methods (Brown and Warner (1985)) over a three-day window around the announcement date using the difference between NYSE or Nasdaq stock returns and the market model measured by the Center for Research in Securities Prices (CRSP) equally weighted index. ${ }^{29}$ The average aquirer's cumulative return in our sample of mergers among S\&P 1500 firms is $-2.5 \%$.

\section{[Table 8 here]}

Column (1) of Table 8 presents estimates from this regression. The $Z_{i j t}$ include the relative size of the two firms (Moeller, Schlingemann, and Stulz (2004), Alexandridis et al. (2011)), the logarithm of the total transaction value, and indicators for whether the deal was unsolicited (Schwert (2000)) and whether payment was made primarily in cash (Huang

\footnotetext{
${ }^{29}$ We obtain similar results with alternative methods for computing cumulative returns (e.g., using different event windows and alternative proxies for the market model).
} 
and Walking (1987), Travlos (1987)). The presence of a contemporaneous interlock lowers announcement returns by 1.8 percentage points on average and the coefficient is statistically significant at the $5 \%$ level. $^{30}$ The coefficient on historical interlocks is positive but not statistically significant. ${ }^{31}$

We do find, however, that historically-interlocked deals are associated with lower variability in announcement returns. Specifically, the standard deviation of announcement returns is 0.51 percentage points for deals where the acquirer and target are historically interlocked and 0.69 percentage points for deals when they are not. A variance-ratio test indicates that this difference is significant at the $1 \%$ level.

To examine whether extreme negative outcomes are less likely for historically-interlocked deals, we compute the percentage of deals without a historical interlock that have announcement returns lying more than one standard deviation below the mean of deals without a historical interlock. This one standard deviation cutoff lies at $-0.91 \%$, and $13.5 \%$ of deals without a historical interlock lie beneath it. In contrast, only $11.1 \%$ of historically-interlocked deals have announcement returns below this cutoff. The paucity of extreme negative announcement returns for historically-interlocked deals relative to their counterparts without a historical interlock is even more pronounced when we choose a more extreme cutoff: $4.3 \%$ of deals without a historical interlock have negative announcement returns at least two standard deviations below their mean (i.e., less than -1.6 percentage points), while only $2.2 \%$ of historically-interlocked deals have cumulative returns below this lower cutoff.

\footnotetext{
${ }^{30}$ Cai and Sevilir (2010, Table 4) find a positive effect of contemporaneous interlocks on an acquirer's abnormal returns using a finer specification than ours. We found, however, that including additional controls such as industry effects and the Tobin's Q of acquirer and target do not affect our result. We attribute the difference to the fact that our IRRC sample is limited to firms in the S\&P 1500 and thus contains large acquirers and targets whose behavior is more likely to be scrutinized by investors. In this context, it is natural to suppose that investors will penalize mergers associated with potential conflicts of interest (i.e., contemporaneously-interlocked directors).

${ }^{31}$ The fact that we do not find historical interlocks related to higher announcement returns could signal that the acquirer is paying a fair (i.e., informed) price for the target, where overpayment would be associated with negative acquirer returns.
} 
We conclude that evidence in favor of historical interlocks enhancing announcement returns is weak, but evidence that they reduce return variability and extreme negative outcomes is much stronger.

\section{Deal Completion}

We next examine whether announced historically-interlocked deals are more likely to be completed by estimating the following logit equation:

$$
\operatorname{Pr}\left(S_{i j t}=1\right)=\alpha_{1}+\alpha_{2} H_{i j t}+\alpha_{4} I_{i j t}+\alpha_{5} Z_{i j t}+\tau_{t}+\varepsilon_{i j t},
$$

where $S_{i j t}$ is an indicator variable taking a value of unity if an announced acquisition of target $j$ by acquirer $i$ in year $t$ completes successfully and zero otherwise. ${ }^{32}$ Similar to other recent studies of deal completion rates such as Branch, Wang, and Yang (2008), about 15\% of announced deals in our sample fail to complete after announcement. Column (2) of Table 8 regresses deal success on the presence of a historical interlock and the full set of control variables used in column (1). The coefficient on historical interlocks is large and statistically significant at the $1 \%$ level. The marginal effect, computed using the logit odds ratio at the covariate means, indicates that historically-interlocked deals are $9.9 \%$ more likely to complete relative to deals without a historical interlock. At the same time, contemporaneous interlocks do not have statistically significant effects on deal completion times.

To examine whether, from the perspective of acquiring-firm boards and management, historical interlocks reduce uncertainty surrounding deal completion, we compute the standard deviation of completion rates for historically-interlocked deals and those without a historical interlock. The standard deviation of the former is 0.14 , while the standard deviation of deals without a historical interlock is 0.37 . This variance ratio test indicates that this difference is significant at the $1 \%$ level.

\footnotetext{
${ }^{32}$ These data are available from the $S D C$ Platinum Database.
} 


\section{Time-to-Completion}

We next examine whether historical interlocks are completed more rapidly relative to other deals. Rapid integration might reflect greater confidence on the part of the board and management of the acquiring firm. It could also reflect a reduced need to rely on due diligence after the announcement. We estimate the following equation on announced deals that end up being completed successfully:

$$
T_{i j t}=\alpha_{1}+\alpha_{2} H_{i j t}+\alpha_{4} I_{i j t}+\alpha_{5} Z_{i j t}+\tau_{t}+\varepsilon_{i j t}
$$

where $T_{i j t}$ is the number of days between announcement and completion. The average completion time in our sample is 142 days and has a standard deviation for 102 days.

Column (3) of Table 8 regresses completion times on historical interlocks and the full set of controls from column (1). The coefficient on a historical interlock is negative and statistically significant, indicating that historically-interlocked deals take 28 days less on average to be completed. Contemporaneous interlocks, on the other hand, have no significant effect on deal completion times.

With respect to uncertainty in deal completion times, we find that the standard deviation of time-to-completion is 74 days for deals where the acquirer and target share a historical interlock and 117 days for deals where they do not. The variance ratio F-test indicates that this difference is statistically significant at the $1 \%$ level.

\section{F. Summary}

We now pause to summarize the evidence so far about how historical interlocks matter in merger decisions. And while the transfer of information across firms is intuitive and appealing, it is possible that other channels are at work. The psychological bias hypothesis, which predicts that directors choose targets based on agency conflicts stemming from social or network connections, is perhaps the main contender. We have conducted several tests for 
psychological biases, but none indicated that they have an effect on the operation of historical interlocks. Indeed, if historical interlocks operated through social connections, those from targets to potential acquirers (i.e., reverse historical interlocks) would also affect acquisition decisions, but Table 4 shows that this is not the case. Psychological biases could also come into play if socially-connected directors, even if only historically interlocked, have greater influence over acquisitions when they hold more important positions at the acquirer. We test for this in Table 5 and show that it is also not the case.

As discussed above, director-firm matching predicts a spurious correlation between inter-firm director connections and mergers due to similarities among firms. The failure of reverse historical interlocks to predict acquisitions in Table 4, however, provides no support for this alternative, and we offer further evidence against a role for director-firm matching in Section VI below. Cross-firm director connections may be related to mergers because an acquirer's directors are sometimes placed on the target's board to facilitate the deal. But since our historical interlocks specifically omit firms that shared a director within the past two years, they are unlikely to be related with director take-on, i.e., the tendency for an acquirer to add members from a potential target's board in advance of a planned deal.

With respect to deal outcomes, the psychological bias hypothesis predicts that directorconnected deals will perform worse than the average deal. We saw in Table 8 that this is true in the case of abnormal returns for contemporaneously-interlocked firms, but not for historical interlocks.

On the other hand, director experience may well confer information that is useful for identifying suitable targets or negotiating better deal terms. And consistent with the information hypothesis, Table 5 shows that historical interlocks matter more when the interlocked director played a larger role on the potential target's board. We also found that historical interlocks affect merger decisions more when the historically-interlocked director has a larger stake in the acquiring firm (Table 5), his current firm has better corporate governance (Ta- 
ble 6), and the firm pairs are not in close proximity (Table 7). We also saw that historical interlocks favorably influence deal success probabilities and time-to-completion, but that this is not the case for contemporaneous interlocks (Table 8). Finally, historical interlocks are associated with a strong reduction in deal outcome uncertainty for abnormal returns, success probabilities, and times to completion. These results are again consistent with the information hypothesis and inconsistent with agency conflicts driving our main results.

Taken together, our findings are supportive of the information hypothesis and difficult to reconcile with the alternatives, and especially with the psychological bias perspective.

\section{Robustness}

In this section we summarize the results of additional tests to verify our main finding that a historical interlock increases the probability that a given directional firm-pair will merge. The online appendix describes these tests and presents the estimation results.

First, it is possible that firms' choices of directors are outcomes of optimization problems that take firm characteristics as inputs, and that these characteristics also affect the propensity of two firms to merge. Since many unobservable characteristics likely to be relevant for director selection are also persistent, we use a de-meaned linear probability model to address the "spurious correlation" that would arise from director-firm matching. This is equivalent to including fixed effects in a linear regression form of equation (4). We find that historically-interlocked firm pairs are about 7.2 times more likely to merge relative to the average firm pair. This effect is larger than found in our main logit models, but is expected given the downward bias typical in coefficients from binary response models with rare events data. We also allow for time-varying unobservables and calculate that their effects would need to be nearly 10 times larger than the effects of observables to explain the effect of historical interlocks on acquisitions fully. Once director selection based on time-invariant firm-pair effects is considered, further selection on unobservables would need to be 60 times larger than on observables, which seems unlikely. 
We also examine the effects of historical interlocks on merger decisions with matching methods that control for endogeneity bias by comparing the conditional merger probabilities of historically-interlocked firm pairs (the "treatment" group) with observationally similar pairs that are not historically interlocked (the "control" group). Using one, two, and three "nearest-neighbor" matches for each observation in the treatment group, we find that the effects of historical interlocks remain positive, large, and statistically significant.

We next conduct robustness checks on some decisions we made in building the sample. First, we check if our findings change when we define historical interlocks as situations where at least one (or three) years have passed since the director last served on the target's board. The effects of historical interlocks are larger with the one-year window and smaller with the three-year window, which might be expected if the saliency of private information about a potential target diminishes with time, but remain positive and highly statistically significant. We also find that the effects of historical interlocks are nearly the same when we exclude partial share acquisitions from the set of mergers, remove the restriction that announced deals must exceed $\$ 100$ million in value, or allow small-share acquisitions that are at least $10 \%$ of the target's shares.

It is also at least plausible that directors tend to move from smaller to larger firms over their careers given that larger firms tend to have higher director compensation and directors might on average choose larger and more prestigious boards as they gain experience. If true, the firms most likely to be acquirers (i.e., larger firms) would also be those most likely to have historical interlocks with smaller firms (i.e., the most likely targets). Although we already control for the ratio of the assets of the potential acquirer and target in all of our specifications, we estimated specifications where the ratio also enters non-linearly. We also limit the sample to firm pairs of roughly equal size (aquirer-to-target asset ratios between 0.75 and 1.25). In all of these models the effects of historical interlocks remain large, positive, and highly significant statistically. In the restricted sample, we find that 55 percent of all 
historical interlocks come from directors moving from larger to smaller firms. Although this falls to 45 percent when we consider all possible firm pairs, the results suggest that the patterns of director movement described above are much less prevalent in our sample than one might imagine.

\section{Conclusion}

The transfer of information about potential merger targets through the past experience of an acquirer's director is important for decisions in the market for corporate control. We show this by creating measures of inter-firm director linkages from potential targets to potential acquirers. Using a current director's past service at a potential target as a proxy for this information, we find that firms with historical interlocks are more likely to initiate acquisitions with potential targets to which they are linked than those for which they have no historical interlock. Our results indicate an effect of information transfer on acquisition patterns that is independent of other factors such as network connectedness, the tendency for directors to move to a likely target's board prior to acquisition, and observed and unobserved firm characteristics. A series of robustness tests confirm our main findings.

The suggestion that firms can generate synergies through acquisitions but that their ability to do so is inhibited by informational asymmetries appears to be born out in the data (see, for example, Rhodes-Kropf, Robinson, and Viswanathan (2005)). We refine this notion by showing that information frictions specific to firm pairs have a quantifiable effect on acquisition patterns. Though we do not consider the implications for optimal portfolio selection here, the facts that director histories are traceable and that share prices of merger targets tend to rise suggest that there may be some value to investors in better understanding these linkages. 


\section{Online Appendix}

This appendix includes robustness tests of our hypothesis that a historical interlock increases the probability that a given directional firm pair merges. These include issues related to timeinvariant (Section A) and time-varying (Section B) selection of directors, a consideration of matching estimators (Section C), robustness tests for several assumptions applied in forming our main sample (Section D), and the role of the relative size of the potential acquirer and target in determining whether acquisitions occur among historically-interlocked firm pairs (Section E).

\section{A. Time-Invariant Director Selection}

In this section we address the "spurious correlation" that would arise from directorfirm matching using firm-pair specific fixed effects to control for unobservable and timeinvariant features that are specific to an acquirer, target, or acquirer-target pair. These persistent common factors could include industry positioning, product lines, investment advisors, corporate governance structures, network connectedness, CEO entrenchment, board and firm size, presence of antitrust pressure, and profitability, among many others. Because the number of firm pairs increases proportionally with the sample size, constructing these fixed effects is computationally infeasible for binary response models due to the incidental variables problem in which the number of parameters increases in proportion to the number of firm pairs. ${ }^{33}$ Fortunately, consistent estimates can be obtained by de-meaning a linear probability model, which is econometrically equivalent to including these fixed effects.

Table A.1 presents the estimated marginal effects of historical interlocks, using the full sample described in Section III.B and used to estimate equation (4). Column (1) includes only historical interlocks, column (2) adds contemporaneous interlocks to the regression, and

\footnotetext{
${ }^{33}$ Even if these effects were computable, latent variable frameworks such as the logit do not permit computation of the variance of individual effects, so the estimated coefficients are identified only up to a scale factor. This prohibits comparative estimates of how controls for pair-specific effects alter parameter values (Wooldridge (2002), 470).
} 
column (3) includes the complete set of controls from the full specification shown in column (5) of Table 3. In all three equations, a historically-interlocked firms is about 6.5 times more likely to merge relative to an average firm. These estimates are larger than those obtained from our main logit models, which is expected given that the downward-biased coefficients typical of binary response models in rare-events data.

\section{[Table A.1 here]}

\section{B. Time-Varying Director Selection}

While theory suggests that time-invariant unobserved heterogeneity is the most likely form of director selection, in principle time-varying unobserved heterogeneity could be driving the results. To address this, we use the insights developed in Altonji, Elder, and Taber (2005) to gauge the degree to which time-varying director selection might be at play. The technique quantifies the amount of selection bias that would be required to explain the entire effect of director experience on acquisition patterns. ${ }^{34}$

Bellows and Miguel (2009) develop a general statistic that makes no assumptions on the shape of the error distribution. This statistic measures how much greater the influence of unobservables on selection must be relative to the influence of observables on selection to fully remove the estimated effect of the variable of interest. The statistic is $\theta_{r}=\hat{\beta}^{f} /\left(\hat{\beta}^{r}-\hat{\beta}^{f}\right)$, where $\hat{\beta}^{r}$ is the estimated coefficient from a regression with a restricted set of controls and $\hat{\beta}^{f}$ is the coefficient from a regression with the full set of controls. The key choice in constructing this statistic is to select the restricted set of controls appropriately, so we work with several different restricted models. An estimated ratio of unity means that selection on unobservables

\footnotetext{
${ }^{34}$ This procedure is motivated by the insight that the amount of selection on observables conveys information about the amount of selection on unobservables. All that is required is that the amount of selection on observables be at least as large as the amount of selection on unobservables. Altonji et al. (2005) argue that this assumption is no less implausible than the assumptions required for OLS estimation.
} 
must be at least as strong as selection on observable characteristics to account for the entire baseline estimate. Similarly, a number greater than one, say 3, would mean that selection on unobservables must be three times greater than selection on observables to attribute the main effect to director selection. Numbers less than one imply that negative selection is present and that the true effect of director experience is in fact larger than the baseline estimates.

Panel B of Table A.1 presents the results, again employing the sample used to estimate equation (4). The first column shows the estimate when the restricted set consists of a constant only. In this case, the statistic indicates that selection on unobservables would need to be almost four times greater than selection on observables to fully explain the effect of historical interlocks on acquisition patterns. A similar result obtains in columns (2) and (3), which respectively add year fixed effects and contemporaneous interlocks. Column (4), which adds the full vector of control variables, provides an estimated statistic of about 4.3.

The finding that firm-pair fixed effects do not cause attrition in the effect of historical interlocks along with the finding that time-varying unobserved heterogeneity is unlikely to affect empirical validity offer evidence that director selection does not play a crucial role in explaining the observed effect of historical interlocks on acquisitions.

\section{Matching Estimators}

We now estimate the effects of historical interlocks on merger decisions using matching methods. These nonparametric estimates control for endogeneity bias by comparing the conditional merger propensities of historically-interlocked firm pairs (the "treatment" group) with observationally similar firm pairs that are not historically-interlocked (the "control" group). In doing so, these estimates also provide an alternative approach to constructing the counterfactual set of firm pairs that are not historically interlocked.

We implement the estimators using the standard two-stage propensity score matching procedure, which uses the sample from equation (4) and estimates a probit regression of a historical interlock on the full vector of firm-pair characteristics and then uses the estimated 
parameters to construct predicted conditional treatment probabilities, i.e., the propensity score (Moffitt (2004)). The propensity scores are then used to form untreated firm pairs to match with each historically-interlocked firm pair. When each treated pair is matched with a single untreated pair, this procedure is known as "one nearest-neighbor matching." The estimated treatment effect is the expected difference in merger probabilities between the treated and control groups (Abadie and Imbens (2006)). For robustness and comparison, we also report unmatched treatment effects along with "two" and "three" nearest-neighbor matching estimates.

\section{[Table A.2 here]}

Table A.2 shows the estimated treatment effects. Panels A through C report unmatched estimators in column (1) along with one, two and three nearest-neighbor matching estimators in columns (2)-(4) using several sampling approaches. Coefficients represent the percent increase in acquisition probability associated with a historical interlock with t-statistics in brackets.

Panel A reports estimates obtained by implementing the matching procedure on a pooled cross-section that includes one observation for each ordered firm pair in the full sample described in Section III.B. The dependent variable takes a value of unity if firm $i$ acquires firm $j$ during the 1996-2006 period and zero otherwise, while the historical interlock takes a value of unity if a firm-pair is historically-interlocked at any point from 1996-2006 and zero otherwise. ${ }^{35}$ The propensity score then uses the full set of firm-pair observables from equation (4) to match each of the 4,488 treated pairs with one, two, or three counterfactual firm pairs drawn from the possible set of 1,401,955 untreated pairs. The two nearest-neighbor matching estimates, for example, are constructed from a sample of 13,464 observations of which 8,976 are untreated. The estimates of the effect of a historical interlock are large and statistically significant in all cases, with a treatment effect of historical interlocks that

\footnotetext{
${ }^{35}$ Similarly, control variables are constructed as means across the 1996-2006 period.
} 
increases the probability firm $i$ acquires firm $j$ by a factor of about 15 for three nearestneighbor matching, which is much larger than the increase implied by the logit estimates in our main analysis (Table 3). This is once again expected given that binary response models lead to downward-biased coefficients in rare-events data.

Panel B reports estimates obtained by implementing the propensity score matching procedure on a cross-section of observations from the year 2004, drawn from the full sample described in Section III.B. The unit of observation is an ordered firm pair, the dependent variable takes a value of unity if firm $i$ acquires firm $j$ and zero otherwise. Here, the matching estimates are based on a sample of 1,212 treated observations that are matched based on propensity score with one, two, and three nearest-neighbors from our untreated set. The two nearest-neighbor matching estimates, for example, are constructed from a sample of 3,636 observations of which 2,424 are untreated. Here again the estimated treatment effects of historical interlocks are positive, large, and statistically significant.

Panel $\mathrm{C}$ restricts the full sample to the subset of firm pairs where both firm $i$ and firm $j$ fall into the same 4-digit SIC code. Here, the set of 905 treated firm pairs is matched with one, two, and three nearest-neighbor subsamples drawn from a universe of untreated firm pairs within 4-digit SIC codes. The estimated treatment effects are again statistically significant with magnitudes similar to those obtained with the pooled cross-section.

These large effects of historical interlocks suggest that neither the number of observations nor assumptions made about the counterfactual set of untreated pairs are driving our main results.

\section{Further Robustness Checks}

We now report results from several additional robustness checks. Our historical interlocks exclude instances where one of the acquirer's current directors served on the potential target's board within the past two years. We did this to avoid cases where the historicallyinterlocked director served on both boards during the merger planning process. 
To check the sensitivity of our results to this assumption, we construct two alternative measures of the historical interlock. In the first, the historical interlock takes a value of unity for a potential acquirer in year $t$ if at least one of its current directors served on the potential target's board in the past, but not in the past year. In the second, the historical interlock takes a value of unity for a potential acquirer in year $t$ if at least one of its current directors served on the potential target's board in the past, but not in the past three years.

\section{[Table A.3 here]}

Columns (1) and (2) of Table A.3 re-estimate the main equation from column (5) of Table 3 by replacing the standard historical interlock with the one-year cutoff (column (1)) and the three-year cutoff (column (2)). The estimated coefficient on a historical interlock is larger in column (1) and smaller in column (2) than in our main results. These findings apply more generally: in additional regressions (not shown) the estimated coefficient on a historical interlock continues to decline gradually as we eliminate observations with more recent board service at the target, possibly reflecting the fact that information becomes outdated as time passes. $^{36}$

We next check whether our main result is sensitive to a more restrictive threshold for the percent of the target bought by the acquirer. Column (3) of Table A.3 presents re-estimates of the main equation from Table 3 , but in this case excludes partial-share acquisitions, i.e., we code $A C Q_{i j t}=1$ only if the purchasing firm acquires $100 \%$ of the target firm's shares in the deal. ${ }^{37}$ The findings are virtually identical to our main results.

We also examine whether our main result is sensitive to inclusion of partial acquisi-

\footnotetext{
${ }^{36}$ We also examined whether the effect of a historical interlock increases with the interlocked director's tenure at the potential target prior to moving to the acquirer, and found there was no statistically signifcant difference between the impact of directors with more or less experience at the target.

${ }^{37}$ This procedure excludes 71 announced mergers from the sample.
} 
tions. We do this by again re-estimating equation (4) retaining only complete acquisitions, i.e., we allow partial share purchases but require that the acquirer own all of the target's shares as a consequence of the deal. ${ }^{38}$ This, for example, includes mergers where the acquirer previously held $20 \%$ of the target's shares and bought $80 \%$ through the deal. The results, presented in Column (4), are nearly identical to our main findings.

We next check to see whether our inclusion of small-value acquisitions affects our main finding. To do this, we include in the main regression only announced deals with a money value greater than 100 million dollars. ${ }^{39}$ These findings are presented in Column (5) with an estimated effect of historical interlocks nearly identical to that in Table 3. Finally, in Column (6), we check the robustness of our results to allowing small-share acquisitions that are at least $10 \%$ of the target's shares. As before, the estimated coefficient on the historical interlock is quite similar to the main coefficient in Table 3.

\section{E. Exploring the Role Played by Relative Size of Acquirer and Potential Target}

It is also at least plausible that directors tend to move from smaller to larger firms over their careers given that larger firms tend to have higher director compensationand directors might on average choose larger and more prestigious boards as they gain experience. If true, the firms most likely to be acquirers (i.e., larger firms) would also be those most likely to have historical interlocks with smaller targets (i.e., smaller firms).

Although we already control for the ratio of the assets of the potential acquirer and target in all of our main specifications, we report further robustness checks for the validity of the alternate story in Table A.4. We begin by checking for nonlinear effects of relative firm size in Column (1), which re-estimates the full specification from Table 3 and includes in addition second- and third-degree polynomials of relative size. These non-linear controls are not statistically significant, and their inclusion does not impact the estimated effect of

\footnotetext{
${ }^{38}$ This restriction eliminates 66 deals from the sample.

${ }^{39}$ This restriction eliminates 54 deals from the sample.
} 
historical interlocks.

[Table A.4 here]

Column (2) re-estimates the main equation on the subsample of matched firm pairs for which the ratio of acquirer and target size is in the interval between 0.75 and 1.25, allowing us to focus on the effect of historical interlocks for similarly-sized firm pairs. The estimated effect of historical interlocks on the probability of acquisition is 6.2 times greater for similarly-sized firms, consistent with the matching estimates presented in Table A.3.

Column (3) re-estimates the main equation from Table 3 and omits the control for relative size. This allows us to examine the relative importance of the size and information channels. The estimated effect of historical interlocks is extremely similar to the main estimate from Table 3, with a historically-interlocked firm pair being about 4.4 times more likely to merge relative to a pair that is not historically interlocked. 


\section{References}

Adams, R. B., and D. Ferreira. "A Theory of Friendly Boards." Journal of Finance, 62 (2007), 217-250.

Adams, R. B.; B. E. Hermalin; and M. S. Weisbach. "The Role of Boards of Directors in Corporate Governance: A Conceptual Framework and Survey." Journal of Economic Literature, 48 (2010), 58-107.

Alexandridis, G.; K. P. Fuller; L. Terhaar; and N. G. Travlos. "Target Size, Acquisition Premiums and Shareholder Gains." Journal of Corporate Finance, (2012), forthcoming.

Almeida, H.; M. Campello; and D. Hackbarth. "Liquidity Mergers." Journal of Financial Economics, 101 (2011), 526-558.

Asch, S. E. "Effects of Group Pressure Upon the Modification and Distortion of Judgment." In Groups, Leadership, and Men: Research in Human Relations, H. S. Guetzkow, ed. Pittsburgh, PA: Carnegie Press (1951).

Bizjak, J.; M. Lemmon; and R. Whitby. "Option Backdating and Board Interlocks." Review of Financial Studies, 22 (2009), 4821-4847.

Branch, B.; J. Wang; and T. Yang. "A Note on Takeover Success Prediction." International Review of Financial Analysis, 17 (2008), 1186-1193.

Bruner, R. F. Applied Mergers and Acquisitions. Hoboken, NJ: John Wiley \& Sons, Inc. (2004).

Cai, Y. and Sevilir, M. "Board connections and M\&A transactions." Journal of Financial Economics 103, 327-349 (2011).

Coase, R. H. "The Nature of the Firm." Economica, 4 (1937), 386-405.

Cocco, J., and P. F. Volpin. "Does Asymmetric Information Affect SEOs and M\&A Activity? Evidence from Corporate Pension Plans." Working Paper, London Business School (2009).

Custodio, C., and D. Metzger. "The Value of CEOs' Industry Expertise: Evidence from Mergers and Acquisitions." Working Paper, London School of Economics (2010).

Davis, G. F. "Agents Without Principles? The Spread of the Poison Pill through the InterCorporate Network." Administrative Science Quarterly, 36 (1991), 583-613.

Dierkens, N. "Information Asymmetry and Equity Issues." Journal of Financial and Quantitative Analysis, 26 (1991), 181-199. 
Demb, A., and F. Neubauer. The Corporate Board: Confronting the Paradoxes. New York: Oxford University Press (1992).

Dong, M.; D. Hirshleifer; S. Richardson; and S. H. Teoh. "Does Investor Misvaluation Drive the Takeover Market?" Journal of Finance, 61 (2006), 725-762.

Eckbo, B. E.; R. M. Giammarino; and R. L. Heinkel. "Asymmetric Information and the Medium of Exchange in Takeovers: Theory and Tests." Review of Financial Studies, 3 (1990), 651-675.

Eckbo, B. E.; V. Maksimovic; and J. Williams. "Consistent Estimation of Cross-Sectional Models in Event Studies." Review of Financial Studies, 3 (1990), 343-365.

Finkelstein, S.; Hambrick, D.; and Cannella, A. Jr. Strategic Leadership: Theory and Research on Executives, Top Management Teams, and Boards. Oxford Press (2008).

Fisher, A. A., and R. H. Lande. "Efficiency Considerations in Merger Enforcement." California Law Review, 71 (1983), 1580-1696.

Freeman, L. C. "Centrality in Social Networks: Conceptual Clarification." Social Networks, 1 (1979), 215-239.

Gompers, P. A.; A. Metrick; and J. L. Ishii. "Corporate Governance and Equity Prices." Quarterly Journal of Economics, 118 (2003), 107-156.

Gompers, P. A., and Y. Xuan. "Bridge Building in Venture Capital-Backed Acquisitions." Working Paper, Harvard Business School (2009).

Gulati, R., and J. D. Westphal. "Cooperative or Controlling? The Effects of CEO-Board Relations and the Content of Interlocks on the Formation of Joint Ventures." Administrative Science Quarterly, 44 (1999), 473-506.

Harford, J. "What Drives Merger Waves?" Journal of Financial Economics, 77 (2005), 529560.

Harris, M., and A. Raviv. "A Theory of Board Control and Size." Review of Financial Studies, 21 (2008), 1797-1832.

Haunschild, P. R. "Interorganizational Imitation: The Impact of Interlocks on Corporate Acquisition Activity." Administrative Science Quarterly, 38 (1993), 564-592.

Hermalin, B. E., and M. S. Weisbach. "Boards of Directors as an Endogenously Determined Institution: A Survey of the Economic Literature." Federal Reserve Bank of New York Economic Policy Review, 9 (2003), 7-26.

Higgins, M. J., and D. Rodriguez. "The Outsourcing of R\&D through Acquisitions in the Pharmaceutical Industry." Journal of Financial Economics, 80 (2006), 351-383. 
Hoberg, G., and G. Phillips. "Product Market Synergies and Competition in Mergers and Acquisitions: A Text Based Analysis." Review of Financial Studies, 23 (2010), 37733811.

Huang, Y. S., and R. A. Walking. "Target Abnormal Returns Associated with Acquisition Announcements." Journal of Financial Economics, 19 (1987), 329-349

Ishii, J. L., and Y. Xuan. "Acquirer-Target Social Ties and Merger Outcomes," Working Paper, Harvard Business School (2010).

Jarrell, G. A., and A. B. Poulsen. "The Returns to Acquiring Firms in Tender Offers: Evidence from Three Decades." Financial Management, 18 (1989), 12-19.

Jovanovic, B., and P. L. Rousseau. "The Q-Theory of Mergers." American Economic Review, 92 (2002), 198-204.

Jovanovic, B., and P. L. Rousseau. "Mergers as Reallocation." Review of Economics and Statistics, 90 (2008), 765-776.

Krishnaswami, S., and V. Subramaniam. "Information Asymmetry, Valuation, and the Corporate Spin-Off Decision." Journal of Financial Economics, 53 (1999), 73-112.

Levit, D. "Expertise, Structure, and Reputation of Corporate Boards." Working Paper, Wharton School, University of Pennsylvania, (2012).

Levit, D., and N. Malenko. "The Labor Market for Directors, Reputational Concerns and Externalities in Corporate Governance." Working Paper, Wharton School, University of Pennsylvania, (2012).

Loderer, C., and K. Martin. "Corporate Acquisitions by Listed Firms: The Experience of a Comprehensive Sample." Financial Management, 19 (1990) 17-33.

Mace, M. Directors: Myth and Reality. Boston: Harvard Business School Press (1986).

Masulis, R. W.; C. Wang; F. Xie. "Corporate Governance and Acquirer Returns." Journal of Finance, 62 (2007), 1851-1889.

McNichols, M. F., and S. R. Stubben. "The Role of Target Firms' Accounting Information in Acquisitions." Working Paper, Stanford University (2009).

Moeller, S. B.; F. P. Schlingemann; and R. M. Stulz. "Firm Size and the Gains from Acquisitions." Journal of Financial Economics, 73 (2004) 201-228.

Moeller, S. B.; F. P. Schlingemann; and R. M. Stulz. "How Do Diversity of Opinion and Information Asymmetry Affect Acquirer Returns?" Review of Financial Studies, 20 (2007), 2047-2078. 
Mueller, D. C. "A Theory of Conglomerate Mergers." Quarterly Journal of Economics, 83 (1969), 643-659.

Myers, S. C., and N. S. Majluf. "Corporate Financing and Investment Decisions When Firms Have Information That Investors Do Not Have." Working Paper No. 1396, National Bureau of Economic Research (1984).

Rhodes-Kropf, M.; and D. T. Robinson. "The Market for Mergers and the Boundaries of the Firm." Journal of Finance, 63 (2008), 1169-1211.

Rhodes-Kropf, M.; D. T. Robinson; and S. Viswanathan. "Market Valuation and Merger Waves: The Empirical Evidence." Journal of Financial Economics, 77 (2005), 561-603.

Rhodes-Kropf, M., and S. Viswanathan. "Market Valuation and Merger Waves. The Journal of Finance, 59 (2004), 2685-2718.

Roll, R. "The Hubris Hypothesis of Corporate Takeovers." Journal of Business, 59 (1986), $197-216$.

Salant, S. W.; S. Switzer; and R. J. Reynolds. "Losses from Horizontal Merger: The Effect of an Exogenous Change in Industry Structure on Cournot-Nash Equilibrium." Quarterly Journal of Economics, 98 (1983), 185-199.

Schonlau, R., and P. V. Singh. "Board Networks and Merger Performance." Working Paper, Carnegie Mellon University (2009).

Schwert, G. W. "Hostility in Takeover: in the Eyes of the Beholder?" Journal of Finance, 55 (2000), 2599-2640.

Shleifer, A., and R. W. Vishny. "Stock Market Driven Acquisitions." Journal of Financial Economics, 70 (2003), 295-311.

Shumway, T. "Forecasting Bankruptcy More Accurately: A Simple Hazard Model." Journal of Business, 74 (2001), 101-124.

Song, F., and A. V. Thakor. "Information Control, Career Concerns and Corporate Governance." Journal of Finance, 61 (2006), 1845-1896.

Stroup, C. "International Experience and Cross-Border Mergers." Working Paper (2012).

Stuart, T. E., and S. Yim. "Board Interlocks and the Propensity to be Targeted in Private Equity Transactions." Journal of Financial Economics, 97 (2010), 174-189.

Travlos, N. G. "Corporate Takeover Bids, Methods of Payment, and Bidding Firms' Stock Returns." Journal of Finance, 42 (1987), 943-963. 


\section{Table 1}

\section{Inter-firm Director Connections}

Panel A shows the distribution of the total number of firms where directors served from 1996 to 2006 (left panel) and, at the director-year level, the distribution of the number of simultaneous board seatings held by a given director at a point in time (right panel). Panel $\mathrm{B}$ shows the percentage of historically and contemporaneously-interlocked directors at the potential acquirer or target that during their tenure served as an executive, inside director, were ever a former employee, or were identified as a 'professional director' by the IRRC.

\section{Panel A. Director Seating Patterns}

\begin{tabular}{ccc}
\multicolumn{3}{c}{ Director Firm } \\
\hline$\#$ & Frequent \\
1 & 6005 & Percent \\
2 & 4862 & $18.1 \%$ \\
3 to 5 & 7635 & $28.5 \%$ \\
6 to 10 & 5940 & $22.2 \%$ \\
$10+$ & 2355 & $8.8 \%$ \\
All & 26,797 & $100 \%$
\end{tabular}

\begin{tabular}{crr}
\multicolumn{3}{c}{ Annual Seat Count } \\
\hline$\#$ & Frequency & Percent \\
1 & 104,860 & $81.1 \%$ \\
2 & 16,573 & $12.8 \%$ \\
3 to 5 & 7,644 & $5.9 \%$ \\
6 to 10 & 254 & $0.2 \%$ \\
& & \\
All & 129,331 & $100 \%$
\end{tabular}

Panel B. Role of Interlocked Directors

\begin{tabular}{|c|c|c|c|c|c|c|}
\hline & \multicolumn{4}{|c|}{ Historically-Interlocked } & \multirow{2}{*}{\multicolumn{2}{|c|}{$\begin{array}{c}\text { Contemporaneously } \\
\text { Interlocked }\end{array}$}} \\
\hline & \multicolumn{2}{|c|}{ Potential Acquirers } & \multicolumn{2}{|c|}{ Potential Targets } & & \\
\hline & Freq. & Percent & Freq. & Percent & Freq. & Percent \\
\hline Executive & 6,525 & $38.7 \%$ & 5,775 & $36.4 \%$ & 9,984 & $43.6 \%$ \\
\hline Inside director & 4,232 & $25.1 \%$ & 5,188 & $32.7 \%$ & 6,480 & $28.3 \%$ \\
\hline Former Emp. & 742 & $4.4 \%$ & 1,095 & $6.9 \%$ & 1,259 & $5.5 \%$ \\
\hline Prof. director & 1,079 & $6.4 \%$ & 1,253 & $7.9 \%$ & 962 & $4.2 \%$ \\
\hline Other & 4,283 & $25.4 \%$ & 2,554 & $16.1 \%$ & 4,213 & $18.4 \%$ \\
\hline Total & 16,861 & $100.0 \%$ & 15,865 & $100.0 \%$ & 22,898 & $100.0 \%$ \\
\hline
\end{tabular}




\section{Table 2}

\section{Firm-Level Characteristics}

Panel A compares characteristics of all in-sample acquirers and targets with the mean for all S\&P 1500 firms over the period 1996-2006. Assets is total book value of assets, market capitalization is the total market value of equity computed as common shares outstanding times the fiscal year closing price, and cash-to-assets is the ratio of cash to total book assets. Debt-to-assets is the ratio of short and long-term debt to total assets and sales-to-assets is total sales revenue divided by total assets. The construction of the market-to-book ratio is described in Section IV. All amounts are in millions of U.S. dollars. Panel B shows the frequency of historical and contemporaneous interlocks alone and based on whether the two firms are headquartered in the same county, where historical and contemporaneous interlocks are defined in Section III.A.

Panel A: Firm-Level Descriptive Statistics

\begin{tabular}{|c|c|c|c|c|c|c|}
\hline & \multicolumn{2}{|c|}{ Acquirers } & \multicolumn{2}{|c|}{ Targets } & \multicolumn{2}{|c|}{ S\&P 1500} \\
\hline & Mean & Median & Mean & Median & Mean & Median \\
\hline Total assets & 47,515 & 8,935 & 5,617 & 1,300 & 5,037 & 231.6 \\
\hline Market capitalization & 43,082 & 8,302 & 5,355 & 1,714 & 3,988 & 250.5 \\
\hline Cash-to-assets & 0.07 & 0.04 & 0.09 & 0.04 & 0.12 & 0.05 \\
\hline Debt-to-assets & 0.23 & 0.21 & 0.25 & 0.23 & 0.27 & 0.17 \\
\hline Sales-to-assets & 0.82 & 0.69 & 0.90 & 0.72 & 0.91 & 0.73 \\
\hline Market-to-book & 3.36 & 2.04 & 2.36 & 1.71 & 2.90 & 1.55 \\
\hline
\end{tabular}

Panel B. Cross-Firm Connections for Firm Pairs that Merge

\begin{tabular}{lccccc} 
& $\%$ & & Same County & & $\mathrm{N}$ \\
\cline { 2 - 2 } Historical interlock & $9.1 \%$ & & $3.9 \%$ & & 809 \\
Contemporaneous interlock & $6.3 \%$ & & $1.7 \%$ & & 809 \\
No inter-firm connection & $84.6 \%$ & & $94.4 \%$ & & 809
\end{tabular}




\section{Table 3}

\section{Effects of a Historical Interlock on Match Pairing}

The table reports estimates from logit regressions for the pair-specific match propensity where the dependent variable is unity if firm $i$ announced an acquisition of potential target $j$ in period $t$. The variable of interest is the historical interlock (defined in Section III.A). Column (2) adds an indicator for whether there is a contemporaneous interlock between the two firms. Column (3) adds controls for relative size, relative sales-to-assets, and relative market-to-book ratios. Column (4) includes binary indicators set to unity when the potential pair are in the same 4-digit SIC industry or are headquartered in the same county. Column (4) adds industry fixed effects defined at the major 10-category SIC division. All regressions include fixed effects for years. Robust standard errors clustered at the firm-pair level appear in parentheses beneath the coefficient estimates. ***, and ${ }^{* * *}$ denote statistical significance at the $10 \%, 5 \%$, and $1 \%$ levels, respectively.

\begin{tabular}{|c|c|c|c|c|c|}
\hline Variable & (1) & $(2)$ & $(3)$ & (4) & $(5)$ \\
\hline Historical interlock & $\begin{array}{l}4.440^{* * *} \\
(0.162)\end{array}$ & $\begin{array}{l}4.316^{* * *} \\
(0.176)\end{array}$ & $\begin{array}{l}4.339^{* * *} \\
(0.176)\end{array}$ & $\begin{array}{l}3.888^{* * *} \\
(0.185)\end{array}$ & $\begin{array}{l}3.839^{* * *} \\
(0.189)\end{array}$ \\
\hline $\begin{array}{l}\text { Contemporaneous } \\
\text { interlock }\end{array}$ & & $\begin{array}{l}1.264^{* * *} \\
(0.261)\end{array}$ & $\begin{array}{l}1.282^{* * *} \\
(0.262)\end{array}$ & $\begin{array}{l}1.205^{* * *} \\
(0.256)\end{array}$ & $\begin{array}{l}1.175^{* * *} \\
(0.260)\end{array}$ \\
\hline Relative size & & & $\begin{array}{l}0.003^{* * *} \\
(0.001)\end{array}$ & $\begin{array}{l}0.003^{* * *} \\
(0.001)\end{array}$ & $\begin{array}{l}0.004^{* * *} \\
(0.001)\end{array}$ \\
\hline Relative sales to assets & & & $\begin{array}{l}0.020 \\
(0.013)\end{array}$ & $\begin{array}{l}0.026^{* * *} \\
(0.007)\end{array}$ & $\begin{array}{l}0.032^{* * *} \\
(0.006)\end{array}$ \\
\hline Relative market to book & & & $\begin{array}{l}0.020 \\
(0.013)\end{array}$ & $\begin{array}{l}0.026^{* * *} \\
(0.007)\end{array}$ & $\begin{array}{l}0.032^{* * *} \\
(0.006)\end{array}$ \\
\hline Same 4-digit SIC & & & & $\begin{array}{l}3.133^{* * *} \\
(0.088)\end{array}$ & $\begin{array}{l}3.067^{* * *} \\
(0.113)\end{array}$ \\
\hline Same county & & & & $\begin{array}{l}1.071^{* * *} \\
(0.148)\end{array}$ & $\begin{array}{l}1.141^{* * *} \\
(0.158)\end{array}$ \\
\hline Year fixed effects & yes & yes & yes & yes & yes \\
\hline Industry fixed effects & no & no & no & no & yes \\
\hline Observations (thousands) & 6,952 & 6,952 & 6,952 & 6,952 & 6,951 \\
\hline Pseudo $\mathrm{R}^{2}$ & 0.037 & 0.039 & 0.040 & 0.136 & 0.142 \\
\hline
\end{tabular}




\section{Table 4}

\section{Effects of Interlocks on Match Pairing: Reverse Historical Interlocks}

The table reports estimates from logit regressions for the pair-specific match propensity where the dependent variable equals unity if an acquisition is announced by potential acquirer $i$ for potential target $j$ in period $t$. The variables of interest are historical interlocks in the first row and reverse historical interlocks from the potential target to an acquirer (defined in Section V.A) in the second row. Column (1) includes reverse historical interlocks only and Column (2) adds historical interlocks, while Column (3) adds contemporaneous interlocks. Column (4) adds controls for relative size, sales-to-assets, and market-to-book ratio, and binary indicators for the firm pair being in the same 4-digit SIC industry and for being headquartered in the same county. Column (5) adds fixed effects for industries at the major 10-category SIC division. All estimating equations include fixed effects for years. Robust standard errors clustered at the firm-pair level appear in parentheses beneath the estimated coefficients. ***, and *** denote statistical significance at the $10 \%, 5 \%$, and $1 \%$ levels.

\begin{tabular}{|c|c|c|c|c|c|}
\hline Variable & $(1)$ & $(2)$ & $(3)$ & $(4)$ & $(5)$ \\
\hline Historical interlock & & $\begin{array}{l}4.437^{* * *} \\
(0.163)\end{array}$ & $\begin{array}{l}4.305^{* * *} \\
(0.177)\end{array}$ & $\begin{array}{l}3.877^{* * *} \\
(0.186)\end{array}$ & $\begin{array}{l}3.829^{* * *} \\
(0.190)\end{array}$ \\
\hline $\begin{array}{l}\text { Reverse historical } \\
\text { interlock }\end{array}$ & $\begin{array}{c}0.550 \\
(0.620)\end{array}$ & $\begin{array}{c}0.285 \\
(0.605)\end{array}$ & $\begin{array}{l}-1.068^{*} \\
(0.632)\end{array}$ & $\begin{array}{l}-0.926 \\
(0.645)\end{array}$ & $\begin{array}{l}-0.904 \\
(0.646)\end{array}$ \\
\hline $\begin{array}{l}\text { Contemporaneous } \\
\text { interlock }\end{array}$ & & & $\begin{array}{l}1.475^{* * *} \\
(0.268)\end{array}$ & $\begin{array}{l}1.381^{* * *} \\
(0.268)\end{array}$ & $\begin{array}{l}1.348^{* * *} \\
(0.273)\end{array}$ \\
\hline Relative size & & & & $\begin{array}{l}0.003^{* * *} \\
(0.001)\end{array}$ & $\begin{array}{l}0.004^{* * *} \\
(0.001)\end{array}$ \\
\hline Relative sales-to-assets & & & & $\begin{array}{c}0.004 \\
(0.008)\end{array}$ & $\begin{array}{c}0.005 \\
(0.007)\end{array}$ \\
\hline Relative market-to-book & & & & $\begin{array}{l}0.026^{* * *} \\
(0.007)\end{array}$ & $\begin{array}{l}0.032^{* * *} \\
(0.006)\end{array}$ \\
\hline Same 4-digit SIC & & & & $\begin{array}{l}3.133^{* * *} \\
(0.088)\end{array}$ & $\begin{array}{l}3.066^{* * *} \\
(0.113)\end{array}$ \\
\hline Same county & & & & $\begin{array}{l}1.065^{* * *} \\
(0.148)\end{array}$ & $\begin{array}{l}1.136^{* * *} \\
(0.158)\end{array}$ \\
\hline Year fixed effects & yes & yes & yes & yes & yes \\
\hline Industry fixed effects & no & no & no & no & yes \\
\hline Observations (thousands) & 6,952 & 6,952 & 6,952 & 6,952 & 6,951 \\
\hline Pseudo $R^{2}$ & 0.008 & 490.036 & 0.038 & 0.136 & 0.142 \\
\hline
\end{tabular}




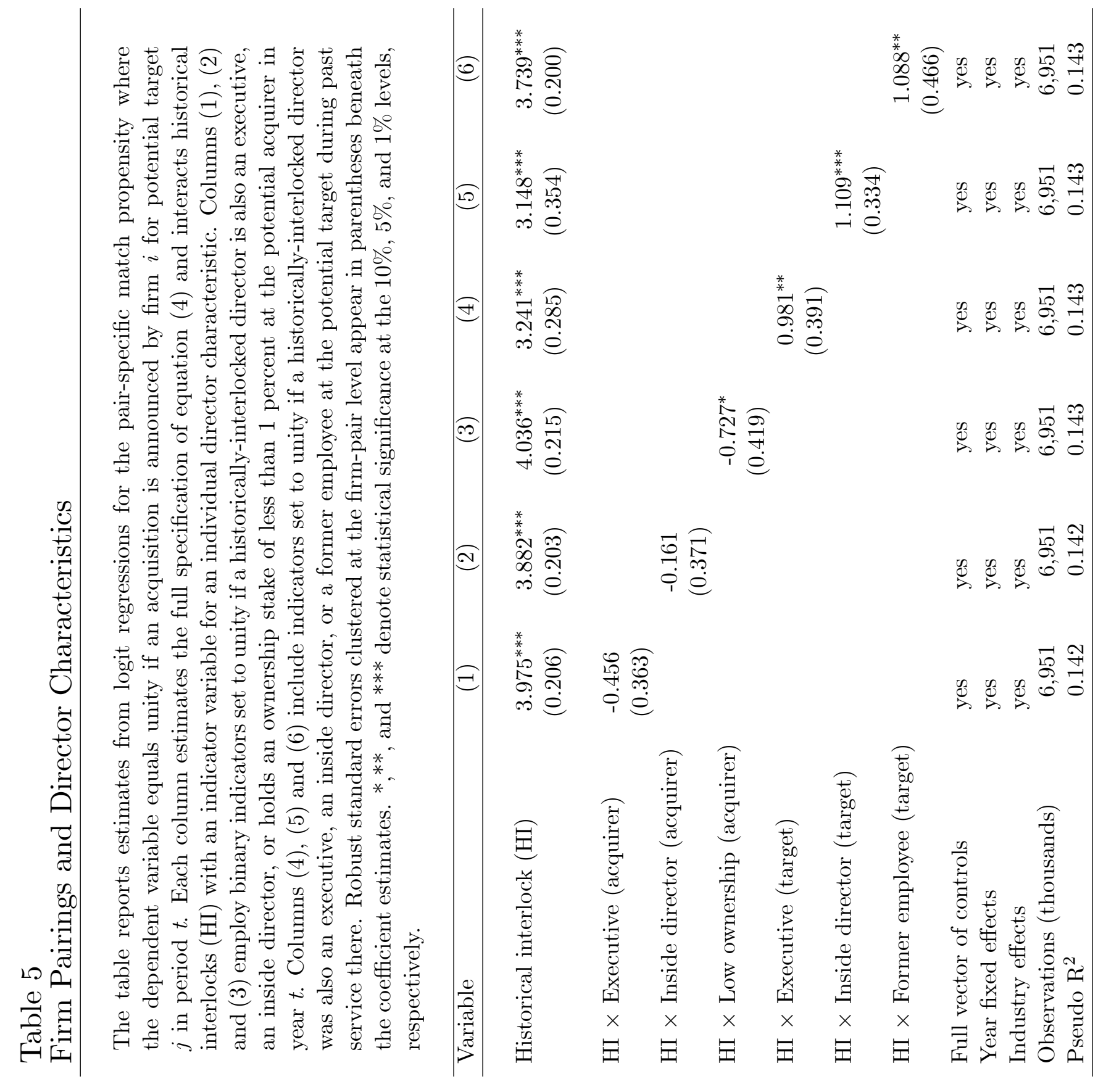




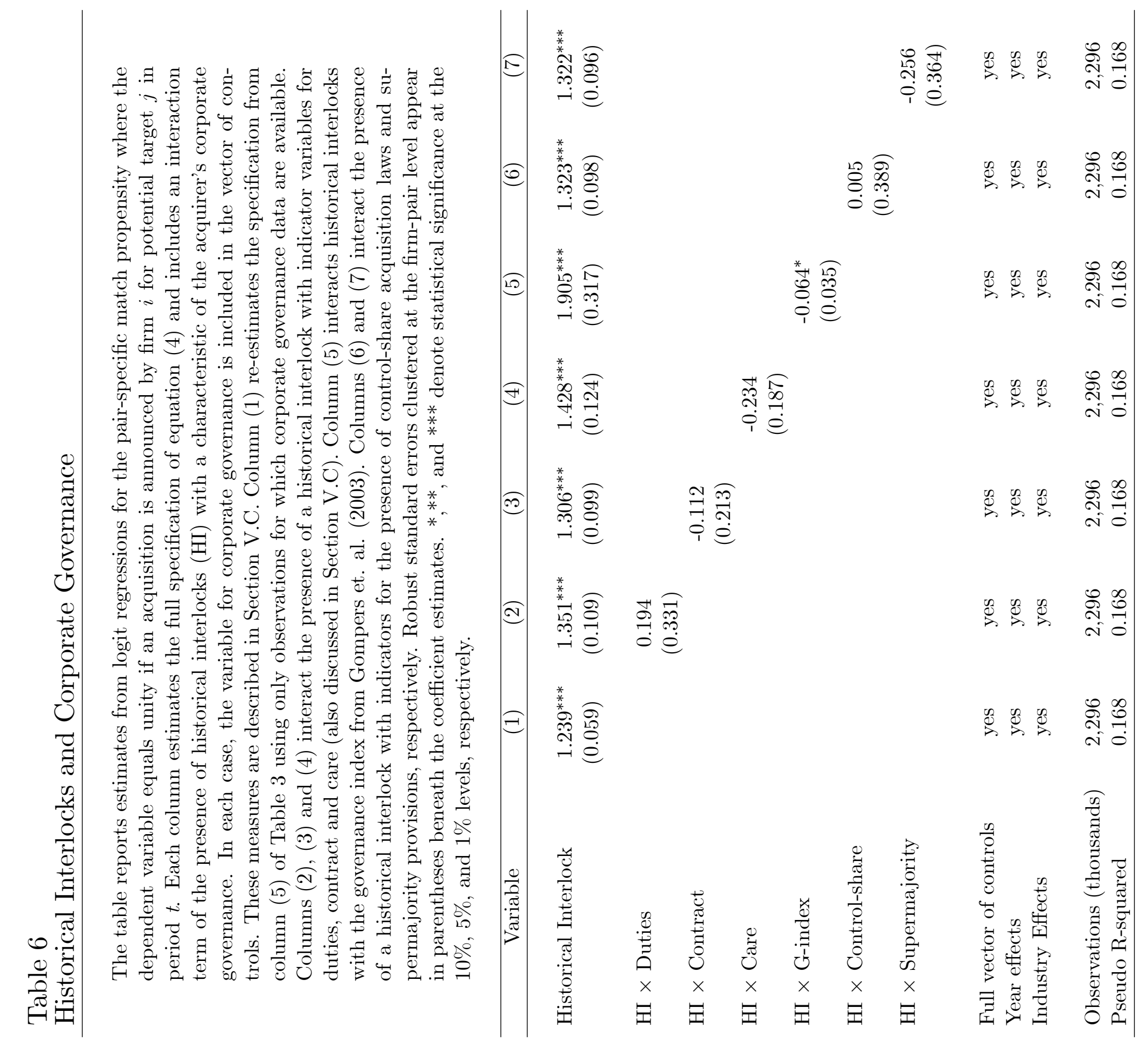


Table 7

Historical Interlocks and the Information Environment

The table reports estimates from logit regressions for the pairspecific match propensity where the dependent variable equals unity if an acquisition is announced by firm $i$ for potential target $j$ in period $t$. The variables of interest are historical interlocks in the first row, contemporaneous interlocks in the second row, and their respective interactions with a binary indicator set to unity if the two firms are headquartered in the same county. All columns estimate the full specification of equation (4) while at the same time including either or both of the interaction terms. Column (1) includes the interaction of the presence of a historical interlock and the same county dummy. Column (2) includes, instead, the interaction of the presence of a contemporaneous interlock and the same county dummy. Column (3) includes both interaction terms. All estimating equations include fixed effects for years and for major 10-category SIC divisions. Robust standard errors clustered at the firm-pair level appear in parentheses beneath the estimated coefficients. ${ }^{*}, * *$, and ${ }^{* * *}$ denote statistical significance at the $10 \%, 5 \%$, and $1 \%$ levels, respectively.

\begin{tabular}{|c|c|c|c|}
\hline Variable & $(1)$ & $(2)$ & $(3)$ \\
\hline Historical interlock (HI) & $\begin{array}{l}4.196^{* * *} \\
(0.185)\end{array}$ & $\begin{array}{l}3.840^{* * *} \\
(0.189)\end{array}$ & $\begin{array}{l}4.211^{* * *} \\
(0.185)\end{array}$ \\
\hline $\begin{array}{l}\text { Contemporaneous } \\
\text { interlock }\end{array}$ & $\begin{array}{l}1.157^{* * *} \\
(0.255)\end{array}$ & $\begin{array}{l}1.101^{* * *} \\
(0.304)\end{array}$ & $\begin{array}{l}1.006^{* * *} \\
(0.308)\end{array}$ \\
\hline $\mathrm{HI} \times$ Same county & $\begin{array}{l}-2.072^{* * *} \\
(0.570)\end{array}$ & & $\begin{array}{l}-2.145^{* * *} \\
(0.596)\end{array}$ \\
\hline CI $\times$ Same county & & $\begin{array}{c}0.284 \\
(0.568)\end{array}$ & $\begin{array}{c}0.586 \\
(0.525)\end{array}$ \\
\hline Full vector of controls & yes & yes & yes \\
\hline Year fixed effects & yes & yes & yes \\
\hline Industry fixed effects & yes & yes & yes \\
\hline Observations (thousands) & 6,951 & 6,951 & 6,951 \\
\hline Pseudo $\mathrm{R}^{2}$ & 0.144 & 0.144 & 0.142 \\
\hline
\end{tabular}




\section{Table 8}

\section{Historical Interlocks and Deal Outcomes}

The table reports estimates of regressions where the dependent variable for an announced acquisition by acquirer $i$ of target $j$ in year $t$ is cumulative announcement returns (Column (1)), an indicator taking a value of one if the deal is closed and zero otherwise (Column (2)) and, for deals that are closed successfully, the number of days between announcement and closing (Column (3)). The variables of interest are the historical and contemporaneous interlocks (defined in Section III.A). The control variables, described in Section V.E, are indicators for whether the deal was a majority cash transaction and whether it was unsolicited, along with the value of the transaction measured in logarithms and the ratio of total assets for the two firms. Robust standard errors appear in parentheses beneath the coefficient estimates. $* * *$, and $* * *$ denote statistical significance at the $10 \%, 5 \%$, and $1 \%$ levels, respectively.

\begin{tabular}{|c|c|c|c|}
\hline & $\begin{array}{c}\text { Announcement } \\
\text { Returms }\end{array}$ & $\begin{array}{c}\text { Deal } \\
\text { Success }\end{array}$ & $\begin{array}{c}\text { Completion } \\
\text { Time }\end{array}$ \\
\hline Variable & (1) & $(3)$ & (6) \\
\hline Historical interlock & $\begin{array}{c}0.002 \\
(0.011)\end{array}$ & $\begin{array}{l}16.424^{* * *} \\
(0.626)\end{array}$ & $\begin{array}{l}-28.199^{* *} \\
(10.762)\end{array}$ \\
\hline $\begin{array}{l}\text { Contemporaneous } \\
\text { Interlock }\end{array}$ & $\begin{array}{l}-0.017^{* *} \\
(0.008)\end{array}$ & $\begin{array}{c}0.936 \\
(0.680)\end{array}$ & $\begin{array}{l}-2.941 \\
(20.732)\end{array}$ \\
\hline Relative size & $\begin{array}{l}0.008^{* * *} \\
(0.002)\end{array}$ & $\begin{array}{l}0.668^{* * *} \\
(0.240)\end{array}$ & $\begin{array}{l}-7.771 \\
(4.867)\end{array}$ \\
\hline Transaction value & $\begin{array}{l}-0.007^{* * *} \\
(0.003)\end{array}$ & $\begin{array}{l}0.390^{* * *} \\
(0.151)\end{array}$ & $\begin{array}{l}16.434^{* *} \\
(5.437)\end{array}$ \\
\hline Cash & $\begin{array}{l}0.024^{* *} \\
(0.005)\end{array}$ & $\begin{array}{c}0.338 \\
(0.386)\end{array}$ & $\begin{array}{l}-8.399 \\
(11.119)\end{array}$ \\
\hline Unsolicited & $\begin{array}{l}0.014^{* *} \\
(0.006)\end{array}$ & $\begin{array}{l}-2.614^{* * *} \\
(0.337)\end{array}$ & $\begin{array}{c}42.611 \\
(28.965)\end{array}$ \\
\hline Year effects & yes & yes & yes \\
\hline Observations & 750 & 750 & 619 \\
\hline R-squared & 0.14 & 0.35 & 0.20 \\
\hline
\end{tabular}




\section{Table A.1}

\section{Linear Fixed Effect Models and}

Estimates of Director Selection

Panel A reports estimates from linear probability models for the pair-specific match propensity expressed as the percent increase in the probability that acquirer $i$ announces an acquisition of potential target $j$ in period $t$. Column (1) includes the historical interlock and year effects only. Column (2) includes contemporaneous interlocks and column (3) includes the full vector of controls from Table 3. All estimating equations include fixed effects for years and for ordered firm pairs. T-statistics derived from robust standard errors clustered at the firmpair level appear in parentheses beneath the coefficient estimates. ${ }^{*}, * *$, and *** denote statistical significance at the $10 \%, 5 \%$, and $1 \%$ levels, respectively. Each cell of Panel B reports ratios based on the coefficient for historical interlocks from regressions on the probability that firm $i$ acquires firm $j$ in year $t$. The ratio is calculated as $\beta^{f} /\left(\beta^{r}-\beta^{f}\right)$, where $\beta^{r}$ is the estimate on historical interlocks obtained from an equation using a restricted set of controls and $\beta^{f}$ is the estimate on historical interlocks from the full regression which includes firm-pair specific fixed effects. The restricted sets of controls are a constant (column (1)), year fixed effects (column (2)), year fixed effects and contemporaneous interlocks (column (3)), and year effects, contemporaneous interlocks, and the full set of controls less firm-pair fixed effects (column (4)).

\section{Panel A: Effect of Historical Interlock from Fixed Effects Model}

\begin{tabular}{|c|c|c|c|c|}
\hline Variable & & (1) & $(2)$ & $(3)$ \\
\hline Historical interlock & & $\begin{array}{l}643.4^{* * *} \\
(4.48)\end{array}$ & $\begin{array}{l}652.4^{* * *} \\
(4.48)\end{array}$ & $\begin{array}{l}652.3^{* * *} \\
(4.48)\end{array}$ \\
\hline Contemporaneous interlock & & & $\begin{array}{l}26.0^{* * *} \\
(2.39)\end{array}$ & $\begin{array}{l}26.0^{* * *} \\
(2.39)\end{array}$ \\
\hline Full vector of controls & & no & no & yes \\
\hline Year fixed effects & & yes & yes & yes \\
\hline Firm-pair fixed effects & & yes & yes & yes \\
\hline \multicolumn{5}{|c|}{ Panel B: Extent of Unobserved Heterogeneity } \\
\hline Variable & (1) & $(2)$ & $(3)$ & $(4)$ \\
\hline$\theta_{r}$ & 3.98 & 3.98 & 4.28 & 4.28 \\
\hline Year fixed effects & no & yes & yes & yes \\
\hline Contemporaneous interlock & no & no & yes & yes \\
\hline Vector of controls & no & no & no & yes \\
\hline Firm-pair fixed effects & yes 54 & yes & yes & yes \\
\hline
\end{tabular}


Table A.2

Matching Estimators

The table reports matching estimates for the pair-specific match propensities. The first column reports unmatched estimates of the average treatment effect. Columns (2), (3) and (4) report one, two and three nearest-neighbor matching estimates of the effect of historical interlocks on acquisitions. Panels A-C report matching estimates obtained from various sampling methods (described in Section $\mathrm{C}$ of this appendix). Average treatment effects are percentage increases relative to the control group. T-statistics appear in parentheses. *, ** and *** denote statistical significance at the $10 \%, 5 \%$, and $1 \%$ levels, respectively.

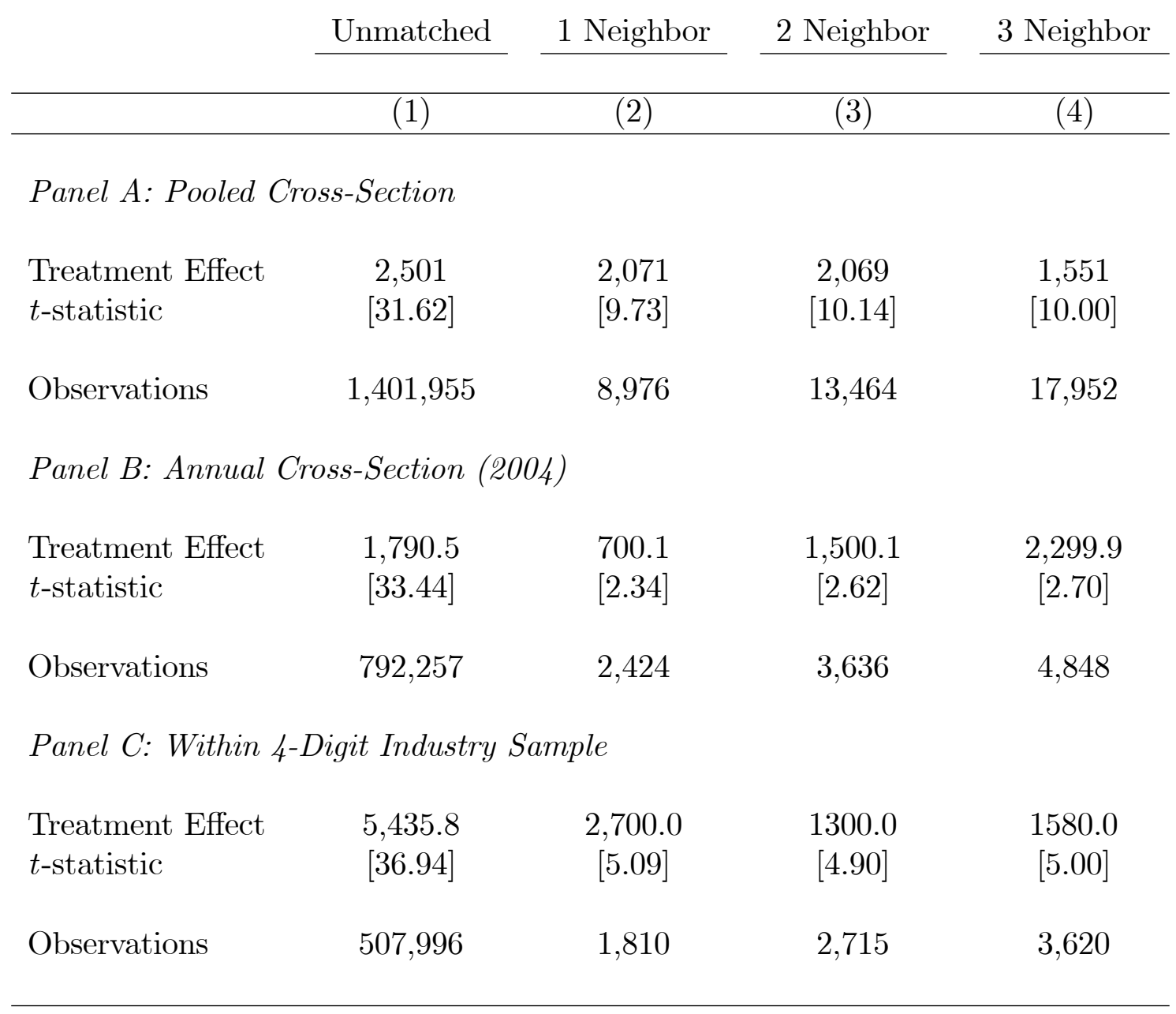




\section{Table A.3 \\ Further Robustness Tests}

The table reports estimates from logit regressions for the pair-specific match propensity where the dependent variable is unity if firm $i$ announced an acquisition of potential target $j$ in period $t$. The variable of interest is the historical interlock (defined in Section III.A). All regressions include the full set of controls used in column 5 of Table 3. Columns (1) and (2) replace the historical interlock with analagous measures (defined in Section D of this appendix) that require a minimal number of years (one and three, respectively), since the historically-interlocked director last served on the target's board. Column (3) excludes partial-share acquisitions from the sample. Column (4) includes partial share acquisitions but requires that the acquirer would own all of the target's shares after the deal. Column (5) requires that deal value be equal to or greater than 100 million U.S. dollars Column (6) requires that the acquirer obtain at least 10 percent of the target as a result of the deal. Robust standard errors clustered at the firm-pair level appear in parentheses beneath the coefficient estimates. ${ }^{*}, * *$, and ${ }^{* * *}$ denote statistical significance at the $10 \%, 5 \%$, and $1 \%$ levels, respectively.

\begin{tabular}{|c|c|c|c|c|c|c|}
\hline Variable & (1) & $(2)$ & $(3)$ & (4) & $(5)$ & $(6)$ \\
\hline Historical interlock & $\begin{array}{l}4.006^{* * *} \\
(0.184)\end{array}$ & $\begin{array}{l}2.406^{* * *} \\
(0.429)\end{array}$ & $\begin{array}{l}3.857^{* * *} \\
(0.195)\end{array}$ & $\begin{array}{l}3.875^{* * *} \\
(0.193)\end{array}$ & $\begin{array}{l}3.890^{* * *} \\
(0.191)\end{array}$ & $\begin{array}{l}3.844^{* * *} \\
(0.190)\end{array}$ \\
\hline $\begin{array}{l}\text { Contemporaneous } \\
\text { interlock }\end{array}$ & $\begin{array}{l}1.609^{* * *} \\
(0.248)\end{array}$ & $\begin{array}{l}1.447^{* * *} \\
(0.247)\end{array}$ & $\begin{array}{l}1.019^{* * *} \\
(0.283)\end{array}$ & $\begin{array}{l}1.155^{* * *} \\
(0.268)\end{array}$ & $\begin{array}{l}1.205^{* * *} \\
(0.269)\end{array}$ & $\begin{array}{l}1.129^{* * *} \\
(0.266)\end{array}$ \\
\hline Relative size & $\begin{array}{l}0.004^{* * *} \\
(0.001)\end{array}$ & $\begin{array}{l}0.004^{* * *} \\
(0.001)\end{array}$ & $\begin{array}{l}0.003^{* * *} \\
(0.001)\end{array}$ & $\begin{array}{l}0.003^{* * *} \\
(0.001)\end{array}$ & $\begin{array}{l}0.002^{* * *} \\
(0.001)\end{array}$ & $\begin{array}{l}0.003^{* * *} \\
(0.001)\end{array}$ \\
\hline Relative sales to assets & $\begin{array}{c}0.004 \\
(0.007)\end{array}$ & $\begin{array}{c}0.004 \\
(0.007)\end{array}$ & $\begin{array}{l}-0.060 \\
(0.037)\end{array}$ & $\begin{array}{l}-0.053 \\
(0.033)\end{array}$ & $\begin{array}{l}0.005 \\
(0.007)\end{array}$ & $\begin{array}{l}0.005 \\
(0.007)\end{array}$ \\
\hline Relative market to book & $\begin{array}{l}0.033^{* * *} \\
(0.005)\end{array}$ & $\begin{array}{l}0.042^{* * *} \\
(0.006)\end{array}$ & $\begin{array}{l}0.032^{* * *} \\
(0.006)\end{array}$ & $\begin{array}{l}0.033^{* * *} \\
(0.006)\end{array}$ & $\begin{array}{l}0.026^{* * *} \\
(0.007)\end{array}$ & $\begin{array}{l}0.042^{* * *} \\
(0.006)\end{array}$ \\
\hline Same 4-digit SIC & $\begin{array}{l}3.070^{* * *} \\
(0.111)\end{array}$ & $\begin{array}{l}3.128^{* * *} \\
(0.111)\end{array}$ & $\begin{array}{l}3.140^{* * *} \\
(0.119)\end{array}$ & $\begin{array}{l}3.110^{* * *} \\
(0.118)\end{array}$ & $\begin{array}{l}3.036^{* * *} \\
(0.117)\end{array}$ & $\begin{array}{l}3.128^{* * *} \\
(0.114)\end{array}$ \\
\hline Same county & $\begin{array}{l}1.107^{* * *} \\
(0.157)\end{array}$ & $\begin{array}{l}1.274^{* * *} \\
(0.151)\end{array}$ & $\begin{array}{l}1.010^{* * *} \\
(0.170)\end{array}$ & $\begin{array}{l}1.086^{* * *} \\
(0.166)\end{array}$ & $\begin{array}{l}1.085^{* * *} \\
(0.166)\end{array}$ & $\begin{array}{l}1.123^{* * *} \\
(0.161)\end{array}$ \\
\hline Year fixed effects & yes & yes & yes & yes & yes & yes \\
\hline Industry fixed effects & yes & yes & yes & yes & yes & yes \\
\hline Observations (thousands) & 6,951 & $\begin{array}{r}6,951 \\
56\end{array}$ & 6,951 & 6,951 & 6,951 & 6,951 \\
\hline Pseudo $\mathrm{R}^{2}$ & 0.142 & 0.122 & 0.144 & 0.147 & 0.141 & 0.146 \\
\hline
\end{tabular}




\section{Table A.4}

\section{Effects of a Historical Interlock on Match Pairing}

The table reports estimates from logit regressions for the pair-specific match propensity where the dependent variable is unity if firm $i$ announced an acquisition of potential target $j$ in period $t$. The estimating equations have the same form as the final column of Table 3 in the main paper. Column (1) includes polynomials of relative firm size. Column (2) restricts the sample to firm pairs for which the potential acquirer and target's relative size lies in the interval $(1.25,0.75)$. Column (3) omits controls for relative size. All regressions include fixed effects for years. Robust standard errors clustered at the firm-pair level appear in parentheses beneath the coefficient estimates. $* * *$, and $* * *$ denote statistical significance at the $10 \%$, $5 \%$, and $1 \%$ levels, respectively.

\begin{tabular}{|c|c|c|c|}
\hline Variable & $(1)$ & $(2)$ & $(3)$ \\
\hline Historical interlock & $\begin{array}{l}3.854^{* * *} \\
(0.189)\end{array}$ & $\begin{array}{l}4.119^{* * *} \\
(0.561)\end{array}$ & $\begin{array}{l}3.810^{* * *} \\
(0.189)\end{array}$ \\
\hline $\begin{array}{l}\text { Contemporaneous } \\
\text { interlock }\end{array}$ & $\begin{array}{l}1.186^{* * *} \\
(0.261)\end{array}$ & $\begin{array}{l}1.194^{* *} \\
(0.577)\end{array}$ & $\begin{array}{l}1.158^{* * *} \\
(0.260)\end{array}$ \\
\hline Relative size & $\begin{array}{l}0.010^{* * *} \\
(0.003)\end{array}$ & $\begin{array}{l}1.371 \\
(1.005)\end{array}$ & \\
\hline Relative size squared & $\begin{array}{l}-0.000 \\
(0.000)\end{array}$ & & \\
\hline Relative size cubed & $\begin{array}{c}0.000 \\
(0.000)\end{array}$ & & \\
\hline Relative sales to assets & $\begin{array}{c}0.004 \\
(0.007)\end{array}$ & $\begin{array}{l}-0.032 \\
(0.060)\end{array}$ & $\begin{array}{l}0.005 \\
(0.007)\end{array}$ \\
\hline Relative market to book & $\begin{array}{l}0.031^{* * *} \\
(0.006)\end{array}$ & $\begin{array}{l}-0.008 \\
(0.042)\end{array}$ & $\begin{array}{l}0.033^{* * *} \\
(0.005)\end{array}$ \\
\hline Same 4-digit SIC & $\begin{array}{l}3.077^{* * *} \\
(0.112)\end{array}$ & $\begin{array}{l}2.770^{* * *} \\
(0.344)\end{array}$ & $\begin{array}{l}3.056^{* * *} \\
(0.114)\end{array}$ \\
\hline Same county & $\begin{array}{l}1.143^{* * *} \\
(0.158)\end{array}$ & $\begin{array}{l}2.219^{* * *} \\
(0.411)\end{array}$ & $\begin{array}{l}1.143^{* * *} \\
(0.159)\end{array}$ \\
\hline Year fixed effects & yes & yes & yes \\
\hline Industry fixed effects & yes & yes & yes \\
\hline Observations (thousands) & 6,951 & 1,121 & 6,951 \\
\hline Pseudo $\mathrm{R}^{2}$ & $0.14 \quad 57$ & 0.20 & 0.14 \\
\hline
\end{tabular}

